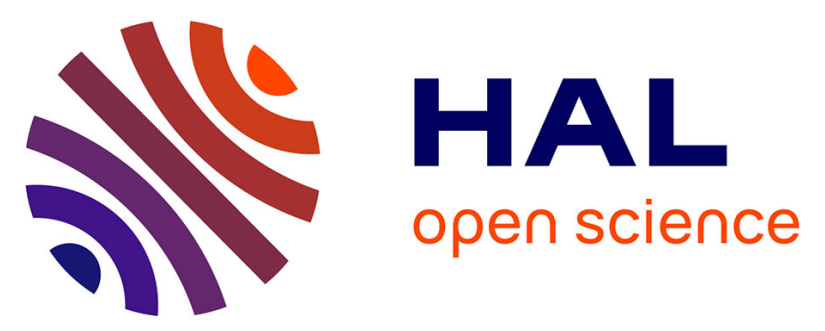

\title{
New insulating and refractory mineral foam: Structure and mechanical properties
}

Mathieu Maréchal, Estefanía del Campo Estrada, Gabrielle Moulin, Giana Almeida, Pin Lv, Gérard Cuvelier, Catherine Bonazzi

\section{- To cite this version:}

Mathieu Maréchal, Estefanía del Campo Estrada, Gabrielle Moulin, Giana Almeida, Pin Lv, et al.. New insulating and refractory mineral foam: Structure and mechanical properties. Materials Science and Engineering: A, 2020, 780, pp.139153. 10.1016/j.msea.2020.139153 . hal-03053165

\section{HAL Id: hal-03053165 \\ https://hal-centralesupelec.archives-ouvertes.fr/hal-03053165}

Submitted on 10 Dec 2020

HAL is a multi-disciplinary open access archive for the deposit and dissemination of scientific research documents, whether they are published or not. The documents may come from teaching and research institutions in France or abroad, or from public or private research centers.
L'archive ouverte pluridisciplinaire HAL, est destinée au dépôt et à la diffusion de documents scientifiques de niveau recherche, publiés ou non, émanant des établissements d'enseignement et de recherche français ou étrangers, des laboratoires publics ou privés. 


\title{
New insulating and refractory mineral foam: structure and mechanical properties
}

\author{
Mathieu Maréchal a, b, Estefanía del Campo Estrada ${ }^{\text {b }}$, Gabrielle Moulin ${ }^{\text {a }}$, Giana Almeida a , \\ Pin $\mathrm{LV}^{\mathrm{c}}$, Gérard Cuvelier ${ }^{\mathrm{a}}$, Catherine Bonazzi ${ }^{\mathrm{a}}$ \\ ${ }^{a}$ Université Paris-Saclay, INRAE, AgroParisTech, UMR SayFood, 91300, Massy, France \\ ${ }^{\mathrm{b}}$ SAS IPSIIS, 77550, Moissy-Cramayel, France \\ ${ }^{\mathrm{c}}$ Université Paris-Saclay, CentraleSupélec, LGPM, SFR Condorcet FR CNRS 3417, Centre Européen de \\ Biotechnologie et de Bioéconomie (CEBB), 51110, Pomacle, France
}

\begin{abstract}
The present work focuses on the structure and mechanical properties of a new type of refractory thermal insulation mineral foam. Studies of the structure of solid foam enabled visualisation of the impact of the formulation and manufacturing processes on the final microstructure.

Solid foam structures were investigated using scanning electron microscopy and X-ray tomography making it possible to reveal and quantify primary porosity, wall porosity, and microstructure, and to better understand the effects of the manufacturing steps. Mechanical compression and bending properties were evaluated on solid and ceramic foams and compared with the properties of commercial insulating mineral materials. At equivalent density, ceramic foam exhibited higher crushing strength than solid foam or commercial samples, with no modification of its microstructure.
\end{abstract}

Keywords: Solid foam, tomography, multi-scale analysis, foaming, porous ceramic material.

\section{Introduction}

Building energy consumption represents over $40 \%$ of the total energy consumed in France, and in Europe fluctuates between $25 \%$ in Luxembourg to more than $45 \%$ to Estonia, Latvia and Hungary (D'Agostino et al. [1]). The number of buildings in the world is expected to double by 2060 . Two thirds of these buildings will be constructed in countries that do not currently have mandatory building energy codes in place. In the African continent alone, this will represent an additional floor area of almost 90 billion $\mathrm{m}^{2}$, more than three times the present African building floor area (Organisation for Economic Co-Operation and Development [2]). Many thermal insulator materials are available on the market which reduce energy costs by up to $60 \%$ (Fragos and Trouillez [3]). Concrete is the main material used for building construction (Flatt et al. [4]), and recent studies (Clément [5], Liu et al. [6], Shimizu et al. [7]) have explored the application of porous plasters, concretes or bricks as insulators to replace standard dense structured materials.

Fire protection is also a key industrial parameter. Internal industry policies promote the reduction of high temperature and fire risks by choosing refractory insulation materials (Fennelly and Perry [8]). In so doing, manufacturers also want to reduce the associated insurance costs. Today, the choice of insulating refractory materials is less diverse than that of other materials used in the building sector, as only mineral insulation materials are available. Because of their high heat resistance, refractory concrete, insulating refractory bricks, and especially refractory ceramic fibre are the most frequently used materials for applications over 
$1,200{ }^{\circ} \mathrm{C}$. Mullite or alumina wool are also used in the case of high temperatures, whereas calcium silicate and microporous materials may be preferred for lower temperatures, typically under $1,000{ }^{\circ} \mathrm{C}$ (Shimizu et al. [7], Promat [9], SISTAC [10] ).

In recent decades, porous ceramics have been developed to withstand high temperatures or corrosive environments (Scheffler and Colombo [11]). Four types of processes for manufacturing macroporous ceramics are reported in the literature: partial sintering, replica technique, sacrificial template, and direct foaming (Studart et al. [12], Colombo [13], Pabst et al. [14], Hammel et al.[15], Nishihora et al. [16]). Direct foaming involves the aeration of a ceramic or pre-ceramic suspension in wet foam that is dried and then sintered to become a ceramic foam. The mineral foam used in the present study can be linked to this method.

Many studies have been conducted on the control and the impact of manufacturing processes on bubble size distribution in wet foam (Kroezen et al. [17], Mary [18], Drenckhan and SaintJalmes [19]). The drying process is also well documented in the literature (Mujumdar [20], Vasseur [21], Vasseur [22]), but many mechanisms, including coarsening, coalescence, drainage, shrinkage, and parameters, including saturated water vapour pressure, and viscosity, can have an impact on the drying step of a foam. Sintering is a thermal finishing treatment to bond particles into a coherent, predominantly solid structure via phenomena that often occur at the atomic scale (German [23]). Sintering involves other mechanisms than drying, as well as high temperatures which mean the material is subject to additional risks (cracks, collapse, melting) if the process is not properly controlled.

The relation between the structure and the mechanical properties of porous materials can be studied using the well-known method of Gibson and Ashby [24]. Different porous structures have been investigated, and several models proposed for foam structures depending on the nature of the pores. The authors assumed that the pores could be approximated by periodic cellular units characterized by edge length and thickness. For open-cell foams, using beam mechanics, their model made it possible to predict variations in the Young modulus or crushing strength as a function of the porosity fraction.

Few studies of highly porous materials like plaster (Clément [5]), concrete (Liu et al. [6]), bricks (Shimizu et al. [7]), or ceramic foam (Bouterf et al. [25]), have combined investigations of the structure and mechanical properties. Thanks to recent advances in imaging techniques, especially X-ray tomography (Vicente et al. [26]), the microstructure of materials is now increasingly frequently studied. Maier et al. [27] recently evaluated ceramic foams using this method.

The present paper analyses a new insulating and refractory material that can solve issues concerning building and industrial infrastructure. We investigated the creation of porosity, the organisation of the structure throughout the foam manufacturing process, and the mechanical properties of material.

The study focussed on identifying structure using a multiscale analysis based on two imaging techniques: scanning electron microscope (SEM) and X-ray tomography. SEM examination provided information on the structure of the macro and microporosity of the foam before and after sintering. By applying two types of protocols at two voxel sizes ( 9 and $1 \mu \mathrm{m}$ ), X-ray tomography provided complementary information on pore distribution and on the total porosity of the material. Mechanical properties were investigated before and after sintering, with compressive and 3-point bending tests. These tests enabled the characterisation of the material and revealed the new properties acquired by sintering. 
2. Preparation and characterisation of foams

2.1. Foam manufacturing process

Foams were manufactured in a 4-step process: mixing, foaming, drying, and sintering (Figure $1)$.

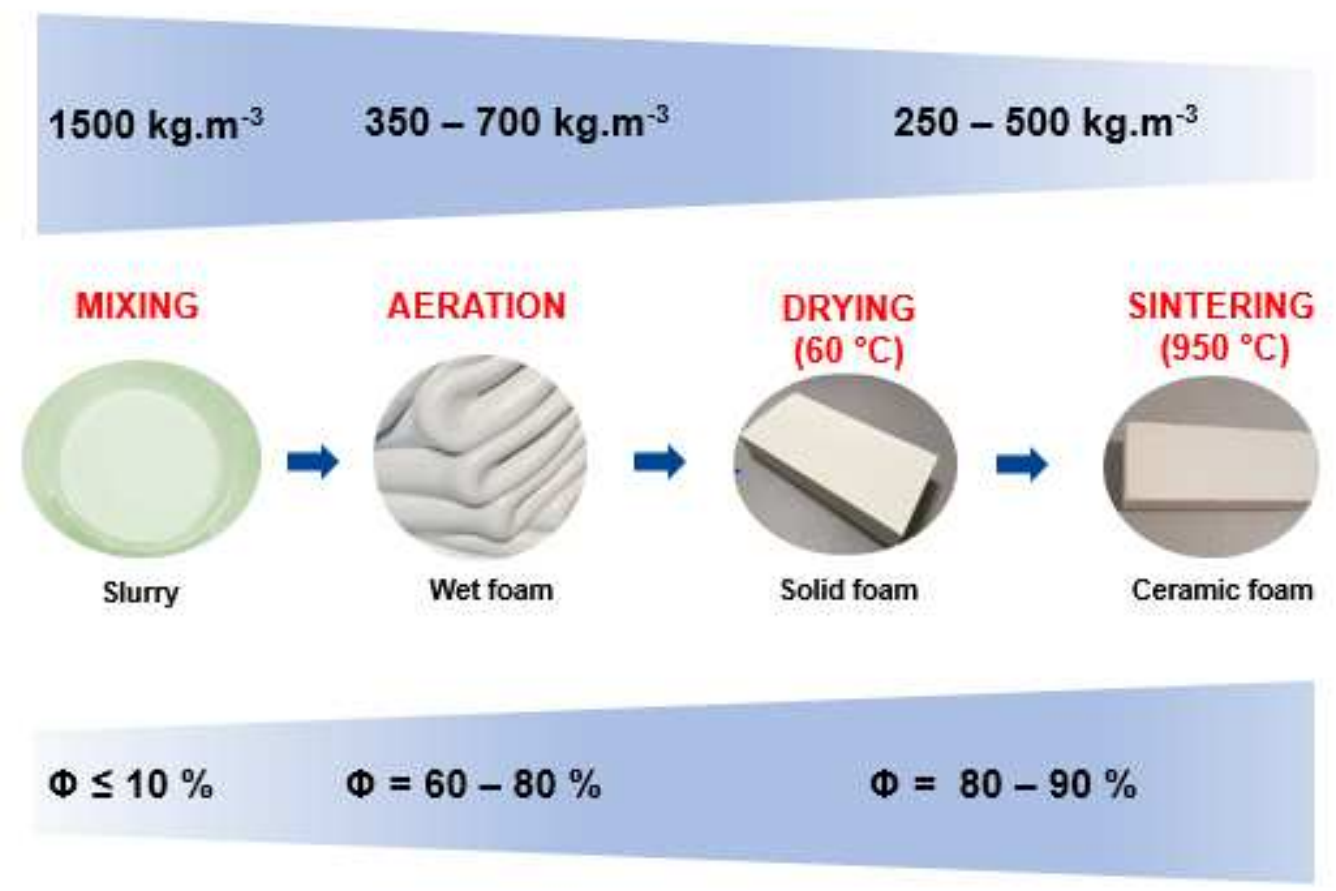

Figure 1: four-step foam manufacturing process.

The manufacturing of foam was based on patent [28]. The slurry was composed of three main ingredients: mineral powder, water and binding agent. The mineral powder was a calcined kaolin Molochite ${ }^{\mathrm{TM}} 72 \mu \mathrm{m}$ (Imerys refractory minerals, Saint Austell, UK), with chemical composition of $54 \% \mathrm{SiO}_{2}, 42 \% \mathrm{Al}_{2} \mathrm{O}_{3}, 2 \% \mathrm{~K}_{2} \mathrm{O}, 1.3 \% \mathrm{Fe}_{2} \mathrm{O}_{3}$, and traces of $\mathrm{MgO}, \mathrm{CaO}$ and $\mathrm{TiO}_{2}$. The binding agent was a mixture of alkali metal silicate solutions (alkali metal of sodium and potassium) from Ceradel-Socor (Paris, France). Organic additives were added as stabilisers of the wet foam (less than $5 \%$ of the slurry), that were then destroyed during the sintering step.

The ingredients were mixed to form a mineral suspension (slurry). The suspension was then loaded into a tank and pumped into a continuous rotor-stator type mixer using a peristaltic pump. Air was co-injected using an El-flow ${ }^{\circledR}$ Select mass flowmeter (Bronkhorst, Ruurlo, NL). After passing the aeration device, the wet foam was pushed through a pipe and poured into a mould. Moulds $(400 \times 490 \times 110 \mathrm{~mm})$ filled with the wet foam, were then placed in a kiln (around $30 \mathrm{~m}^{3}$ ) equipped with two Sauno VT3/2 kW (Logosol, Härnösand, Sweden) temperature controlled $\left(60^{\circ} \mathrm{C}\right)$ in drying units for seven days. The drying step resulted in a solid mineral foam, which was then sintered in a THA $460 \mathrm{~F} / 18 \mathrm{~kW}$ electrical furnace (Enitherm, Deluz, France) to obtain a ceramic foam. The temperature in the furnace was raised from room temperature to $950{ }^{\circ} \mathrm{C}$ in 7 hours, then maintained at constant temperature for $30 \mathrm{~min}$, and finally cooled for 24 hours before the ceramic foam was removed. The final matrix of ceramic foam was only composed of mineral powder and binding agent.

2.2. Samples used for the study 
A single batch of mineral slurry was used for all the experiments. The only change made was to the air injection rate, which was increased from 70 to $160 \mathrm{~L} \cdot \mathrm{h}^{-1}$, in normal temperature and pressure conditions, during the manufacturing of the wet foam. The slurry flow rate and rotor rotation speed were kept constant $\left(50 \mathrm{~L} \cdot \mathrm{h}^{-1}\right.$ and $300 \mathrm{rpm}$, respectively). The moulds were filled with wet foam to a height of approximately $60 \mathrm{~mm}$ at different air injection rates.

Four samples of solid foam hereafter referred to as A, B, C and D, with apparent densities of 500 (A), 370 (B), 320 (C), and 270 (D) kg.m $\mathrm{m}^{-3}$, and four samples of ceramic foam (also named A to D) with apparent densities of 500 (A), 370 (B), 310 (C) and 260 (D) $\mathrm{kg} \cdot \mathrm{m}^{-3}$, were used for the study (Figure 2, (1)).

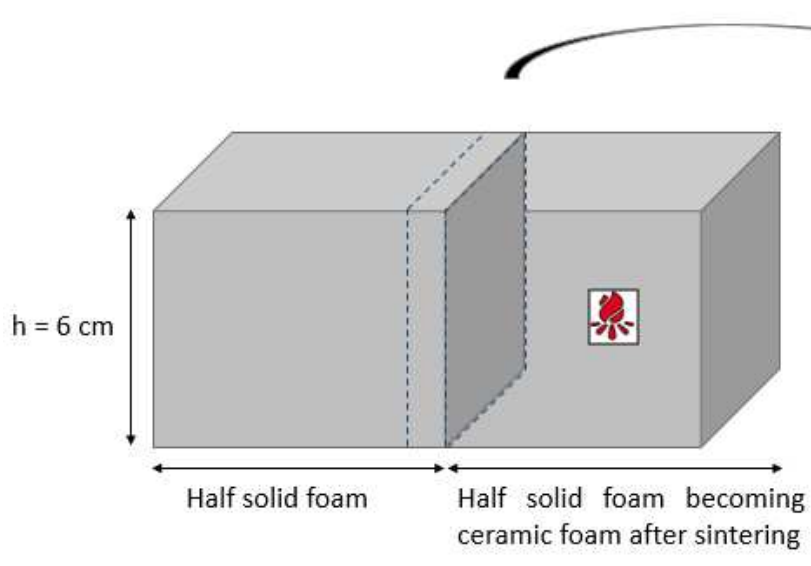

(1)

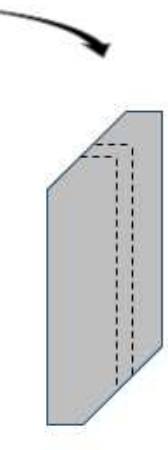

(2)

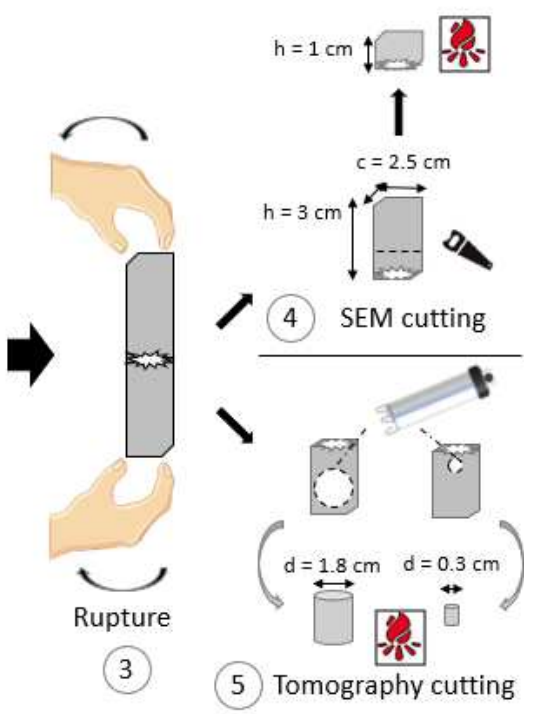

Figure 2: Implementation of one of the foams selected for mechanical tests, SEM and tomography cutting. The red fire symbol means the selected sample was subject to a sintering step at $950{ }^{\circ} \mathrm{C}$.

Figure 2 shows how the foam was prepared for the mechanical tests (compression and 3-point bending) plus the imaging techniques (SEM and X-ray tomography) used.

Each piece of solid foam was cut into two equal parts. Each part was used for mechanical tests. In addition, half of one part was sintered to produce a ceramic foam, giving a total of eight different samples studied (4 densities x 2 conditions, i.e., before and after sintering). For the purpose of comparison, two kinds of highly porous materials suitable for thermal insulation were used to test the mechanical properties: a light SkamoCeramic Hipor 450® brick (Skamol, Tranbjerg, Denmark) with a density of $450 \mathrm{~kg} . \mathrm{m}^{-3}$ (Skamol [29]) and a ultralight Multipor ${ }^{\circledR}$ concrete with a density of $115 \mathrm{~kg} \cdot \mathrm{m}^{-3}$ (Ytong [30]).

The samples were prepared for imaging analysis as follows: a band saw was used to cut the big samples (step (1) and (2)). After cutting the foam in half widthwise (1), the resulting slice was cut lengthwise (2). The foam was ruptured by bending it by hand (3) to obtain a more natural break, since using a cutting machine would probably have modified the true microstructure of the foam. One half was used for SEM analysis, and the other half for tomography analysis. Any excess solid foam was removed with a carbide saw to reach $1 \mathrm{~cm}$ height before SEM analysis (4). Four cylindrical samples of solid foam (named A to D) were obtained using a hole saw with a diameter of $1.8 \mathrm{~cm}$. In addition, a punch with a diameter of $0.3 \mathrm{~cm}$ was used to extract another foam cylinder from sample $\mathrm{C}$. The foam cylinder with a 
diameter of $0.3 \mathrm{~cm}$ was used for $1 \mu \mathrm{m}$-tomography analysis, and the cylinders with an $1.8 \mathrm{~cm}$ diameter were used for $9 \mu \mathrm{m}$-tomography analysis (5). After solid foam analysis (SEM and $\mathrm{X}$-ray tomography), the samples were sintered at $950{ }^{\circ} \mathrm{C}$.

\subsection{Foam structures}

\subsubsection{SEM}

The microstructure of solid and ceramic foams was investigated using a Quanta 200 FEG Environmental Scanning Electron Microscope (ESEM) (FEI, Hillsboro, OR, USA) with the following conditions: secondary electron detector, mode low vacuum, Torr pressure: 0.8, voltage: $10 \mathrm{kV}$. Images of samples A, B, C and D, before and after sintering, were acquired at x100, x400 and x1500 magnification. For easier comparison, SEM images were acquired of exactly the same imaging section before and after sintering to identify any changes caused by the process.

The method used to measure shrinkage is based on Stokes theorem, using a procedure developed by Perré and Huber [31] and described by Almeida et al. [32]. Two shrinkage parameters were mathematically defined, hereafter $X$ - and $Y$-shrinkage axes.

The Meshpore software developed by Perré [33] was used to determine both shrinkage parameters, working with pairs of images of the same foam before (initial) and after (deformed) sintering. A closed chain of material points, chosen as discriminant points of the foam on the initial image, was first plotted and duplicated before switching to the deformed image. By translation on the duplicated chain, each point was then moved to the correct location on the deformed image. Finally, the $X$ and $Y$ shrinkage axes were automatically calculated using the "strain" command (Figure 3).
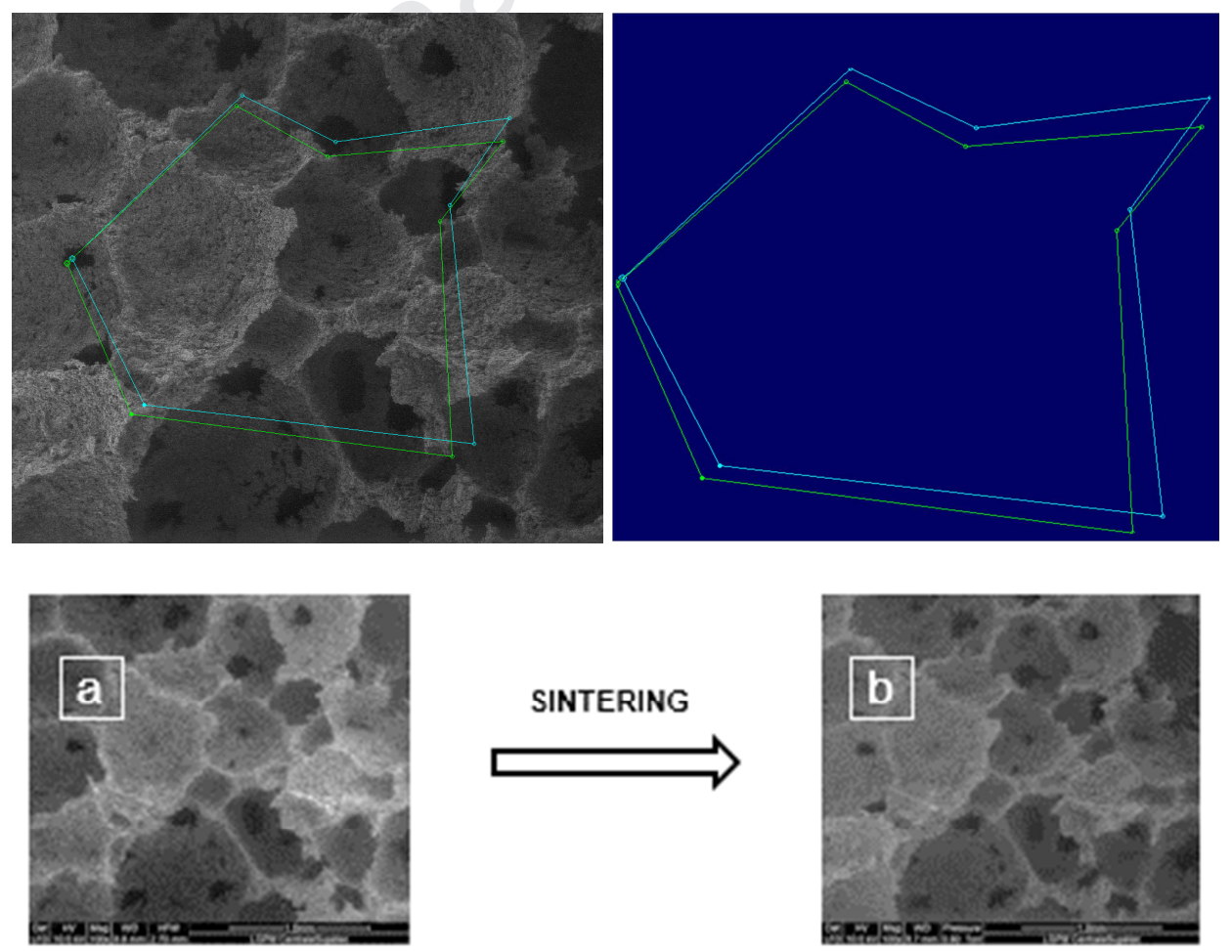

Figure 3: Example of foam shrinkage measurement using Meshpore software in initial (a) and deformed (b) images. Pictures correspond to foam $B$ before and after sintering, with a blue line in the original image and a green line in the deformed image. 


\subsubsection{X-ray tomography analysis}

The microstructure of the mineral foam was explored using X-ray tomography techniques, with voxel sizes of 1 and $9 \mu \mathrm{m}$ to investigate different microstructure levels.

An X-ray micro-computed tomograph ( $\mu-\mathrm{CT}$ ) Desktom 130 (RX Solutions, Chavanod, France) was used for larger scale investigation. An X-ray generator with sealed microfocus tubes in small spot mode (source settings: $8 \mathrm{~W}, 50 \mathrm{kV}$ and $160 \mu \mathrm{A}$ ) was used in the $\mu$-CT chamber. An Option 2520 imager was used to acquire 896 images with an exposure time of $0.4 \mathrm{~s}$ and an averaging frame (i.e. number of images per second) of 2.5. Samples were scanned in $11 \mathrm{~min}$ with a voxel size of $9 \mu \mathrm{m}$ in the $\mu$-CT chamber.

$\mu-\mathrm{CT}$ analysed the sample and produced projections that were compiled to make a 3D reconstruction of the material. The initial quality of the images was improved using XAct $2 \circledR$ (RX Solutions, Chavanod, France) software to remove blur and ring artefacts, and to adjust contrast and brightness. At the end of this step, a 7 × 7 × $10 \mathrm{~mm}$ paving block (Figure 6-A), was extracted for further analysis.

Porosities in the solid materials were quantified after analysis using Simpleware ScanIPTM software (Synopsys, Mountain View, CA, USA). A median filter was applied over neighbours of 1 voxel, and a threshold technique was used to separate the pore and wall fractions (two complementary masks, a wall mask and a pore mask, were produced). After these treatments, the software was able to determine the volume fractions of the pore and the wall at a voxel size of $9 \mu \mathrm{m}$. Watershed algorithm was performed on the pore mask to separate adjacent elements. The option discarding all particles that touched boundaries was also used during watershed algorithm to exclude pores that were not located entirely inside the volume analysed in the study. Figure 7 shows the 3D structure of the foam after watershed algorithm. Afterward, the number and size of the pores was calculated using the calculation functions of the software. The volume of each pore was then converted into an equivalent spherical diameter and the total volume fraction vs the equivalent spherical diameter was drawn.

A nano-computed tomograph (nano-CT) EasyTom XL 150/160 (RX-solutions, Chavanod, France) with $500 \mathrm{~nm}$ maximum voxel size was used to investigate the walls of the foam in more detail before and after sintering. A high temperature, a heat resistant tracker made in metal alloy was glued inside the sample to be sure to analyse exactly the same volume before and after sintering.

Samples were scanned for $4 \mathrm{hrs}$ at a voxel size of $1 \mu \mathrm{m}$, using a nano-focus tube and source settings of $70 \mathrm{kV}$ and $140 \mu \mathrm{A}$. A CCD detector, size $2004 \times 1336 \mathrm{~mm}$ was used, and 1,568 radiographs were acquired with an exposure time of $1.5 \mathrm{~s}$ and an averaging frame of 6 . XAct $2 ®$ was also used to improve contrast and extract a paving block of $1.9 \times 1.9 \times 1.1 \mathrm{~mm}$ for further analysis (Figure 6-B). Post analysis was performed to quantify total porosity using Simpleware ScanIP ${ }^{\mathrm{TM}}$. No median filter was applied to avoid smoothing the walls and losing information on wall porosity. A threshold technique was also used to separate the pore + wall pore fraction in one part and the wall fraction in the other part.

\subsection{Density}

2.4.1. Apparent density 
The four ceramic foams (A, B, C, D) were weighed with $0.01 \mathrm{~g}$ accuracy and their volume was calculated by simply measuring their dimensions with a calliper or a VolScanProfiler 600 (Stable Micro Systems, Godalming, UK).

\subsubsection{Wall density}

An AccuPyc 1330 (Micromeritics, Norcross, GA, USA) air pycnometer was used to determine the density of the mineral foam's wall without porosity. After calibration of the volume of the empty sample chamber, the metal cylinder was filled $2 / 3$ full with crushed foam, and the volume of the porous material was calculated from the pressure by applying Boyle's law. The cylinder was then weighed with and without the powder. Each measurement was made 9 times ( 3 repetitions of 3 analyses for each sample).

\subsection{Mechanical properties}

\subsubsection{Compression}

A TA.HD Plus texture Analyser (Stable Micro Systems, Godalming, UK) with a force capacity of $750 \mathrm{kgf}(7,360 \mathrm{~N})$ equipped with a cylindrical metal plate $10 \mathrm{~cm}$ in diameter $\left(l_{p}\right)$, was used for the compression tests. Cylindrical samples about $38 \mathrm{~mm}$ in diameter and 50-60 $\mathrm{mm}$ in height were used to determine crushing strength $\left(\sigma^{*}\right)$ (Figure $\left.41-\mathrm{A}\right)$. The height of the cylinders was reduced for ceramic foam $\mathrm{A}$, due to a recorded maximum force greater than $7,360 \mathrm{~N}$ that could damage the measuring cell. A prestress level of $2 \mathrm{kPa}$ was applied prior to recording to ensure optimal plate-sample contact. Test speed was $1 \mathrm{~mm} . \mathrm{s}^{-1}$. The crushing strength $\sigma^{*}(\mathrm{MPa})$ was calculated as follows:

$$
\boldsymbol{\sigma}^{*}=\frac{\boldsymbol{F}_{\max }}{\boldsymbol{S}_{\mathbf{0}}}
$$

where $F_{\max }$ is the breaking force in compression and $S_{0}$ is the surface area of the sample before the test.

\subsubsection{Three-point bending test}

The bending properties of the foam (flexural strength and Young modulus), were determined using the same mechanical test machine equipped with a 3-point bending device (Figure 4 1B) at a force capacity of $100 \mathrm{kgf}(981 \mathrm{~N})$.

According to equation (2) and EN NF 310 (AFNOR [34]), the dimensions of test pieces $\left(V_{s}\right)$ of the solid and ceramic foam, and of the commercial materials, were as close as possible to $10 \mathrm{~mm}$ in thickness $(t), 50 \mathrm{~mm}$ in width $(b)$ and $250 \mathrm{~mm}$ in length $\left(L_{2}\right)$ except for the ceramic foams for which $L_{2}$ was shorter. The test speed was $0.01 \mathrm{~mm} . \mathrm{s}^{-1}$ to obtain a rupture after at least $30 \mathrm{~s}$.

$$
V_{s}=t * L_{2} * b=t *(20 t+50) * b
$$

Apparent Young modulus $\left(E^{*}\right.$, in $\mathrm{MPa}$ ) was determined using the following formula (AFNOR [34]):

$$
E^{*}=\frac{l_{1}^{3}\left(F_{2}-F_{1}\right)}{4 b^{3}\left(a_{2}-a_{1}\right)}
$$


where $F_{2}-F_{1}$ is the increase in load on the straight section of the deformation load curve $\left(F_{1} \approx\right.$ $10 \%, F_{2} \approx 40 \%$ of the breaking load, respectively), $a_{2}-a_{1}$ is the increase in deflection at the mid-section of the sample, $l_{l}$ is the distance between the centres of the supports, $b$ is the sample width and $t$ the sample thickness.

Flexural strength ( $\mathrm{F}_{\mathrm{m}}$ in $\left.\mathrm{MPa}\right)$ was determined as follows (AFNOR [34]):

$$
F_{m}=\frac{3 F_{m a x} l_{1}}{2 b t^{2}}
$$

where $F_{\max }$ is the breaking force in bending, $l_{l}$ is the distance between the centres of the supports, $b$ is the sample width and $t$ the sample thickness.

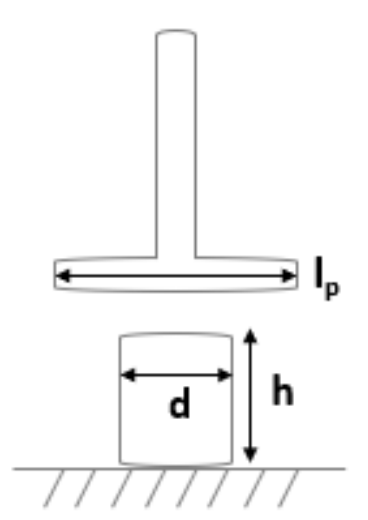

$1-A$

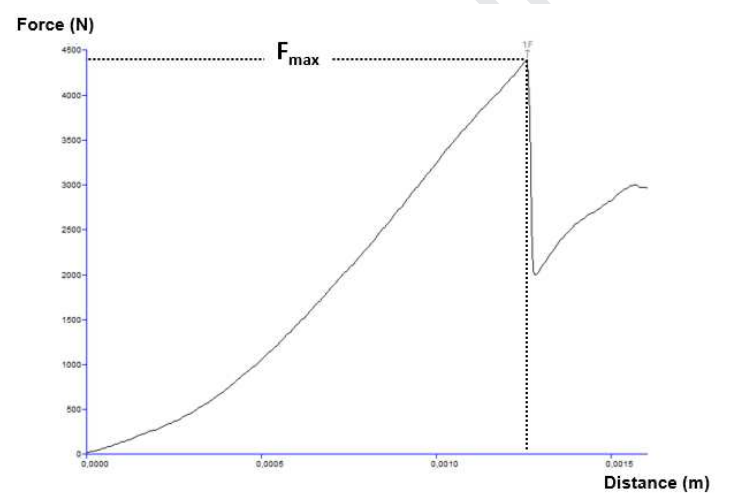

$2-A$

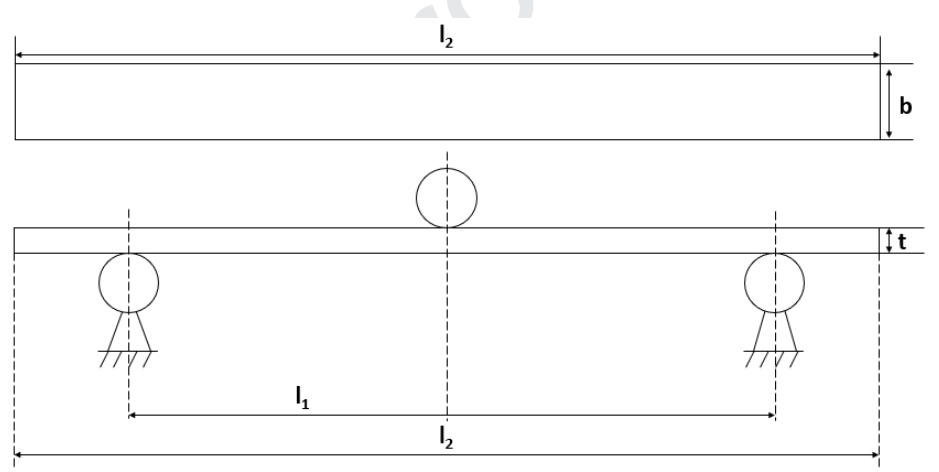

$1-B$

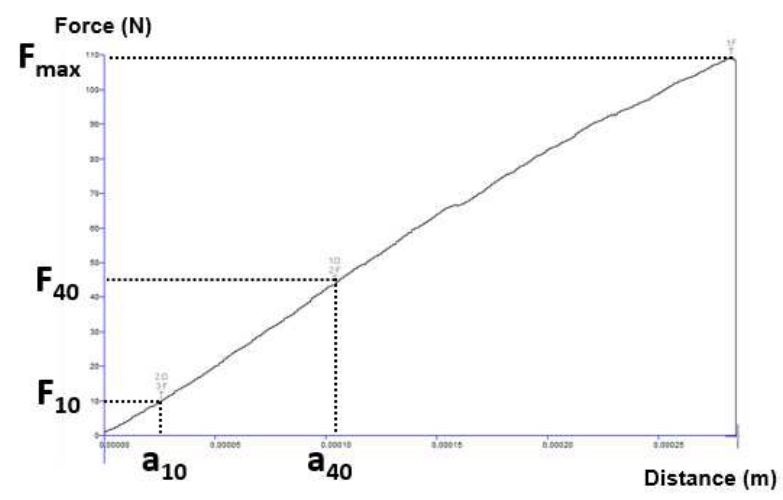

$2-B$

Figure 4: Schematics of the devices (1) and determination methodology (2) used for the compression (A) and 3-point bending test $(B)$. The example of an experimental curve is that of ceramic foam $A$.

\subsubsection{Statistical analysis of the mechanical properties of the samples}

Statistical analysis was performed using XLSTAT 2016 software (Addinsoft, Paris, France). Analysis of variance (ANOVA) was performed to evaluate differences between average values using Tukey's test. Significance level of $p \leq 0.05$ was used.

3. Results 


\subsection{Foam structure}

\subsubsection{SEM}

The images of the foams in Figure 5 were acquired by SEM. They show the surface structure of the solid and ceramic foams with an apparent density ranging from $260-500 \mathrm{~kg} \cdot \mathrm{m}^{-3}$. All the foams had similar structures. They were composed of a mineral matrix surrounding large pores. Observation of solid and ceramic foams at three levels of magnification ( $100, x 400$ and $\mathrm{x} 1,500)$ made it possible to distinguish two kinds of porosity: macroporosity, i.e., most pores were more than $50 \mu \mathrm{m}$ in diameter, named primary porosity, and wall porosity, with smaller pores (diameter $<5 \mu \mathrm{m}$ ). Primary porosity and wall porosity formed a continuous open network.

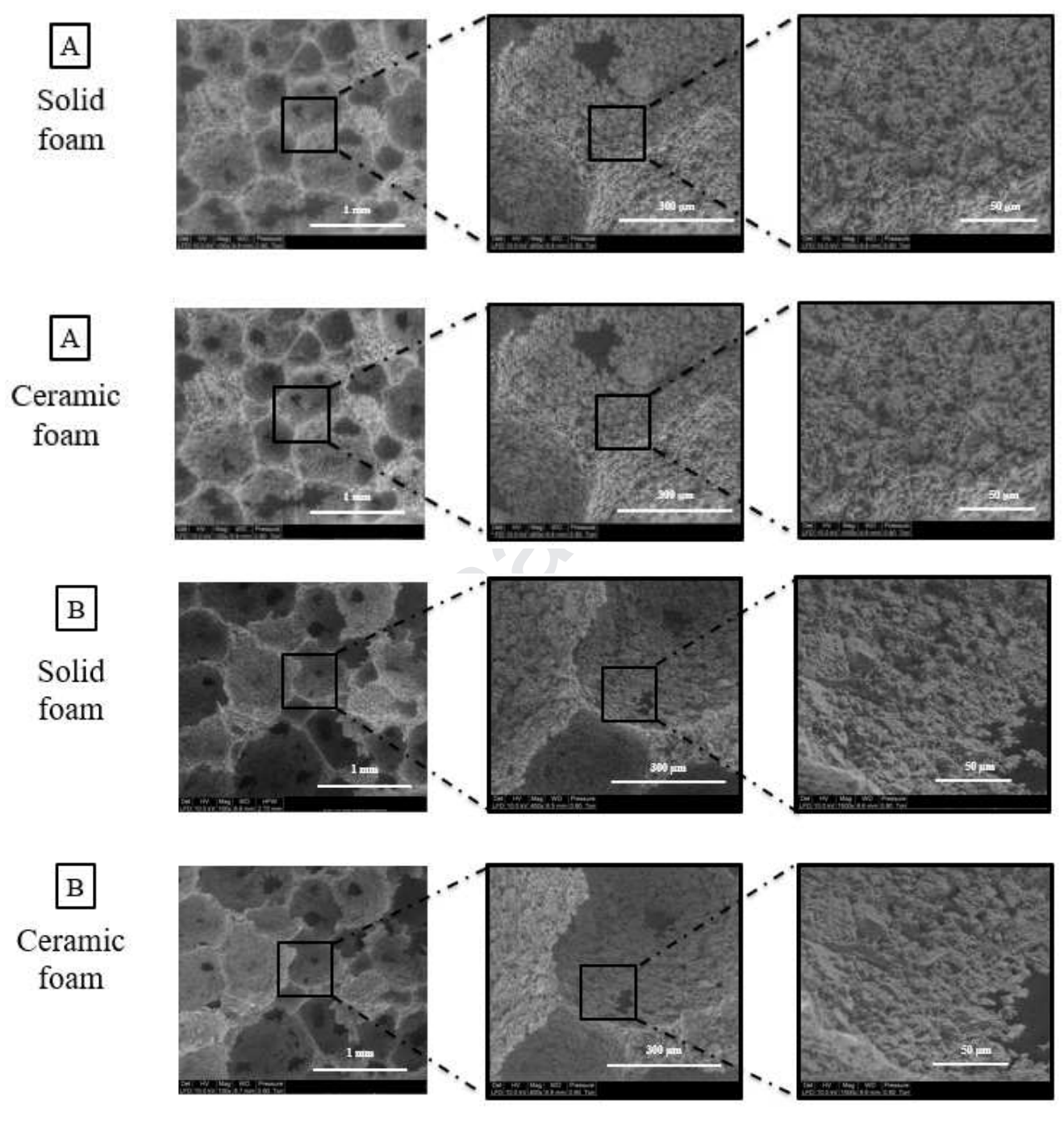




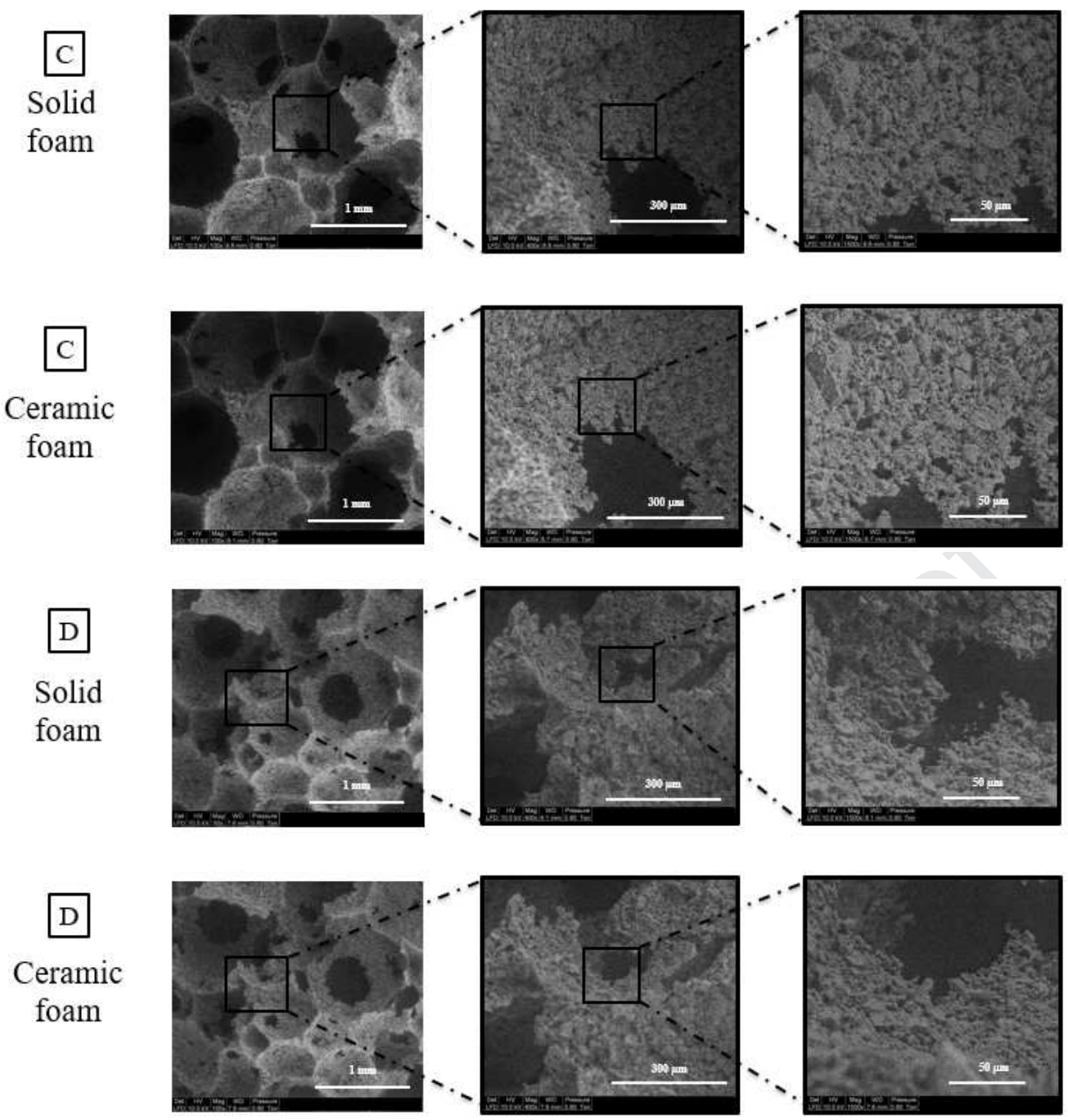

Figure 5: Solid foam before (A: $\left.500 \mathrm{~kg} \cdot \mathrm{m}^{-3}, \mathrm{~B}: 370 \mathrm{~kg} \cdot \mathrm{m}^{-3}, \mathrm{C}: 320 \mathrm{~kg} \cdot \mathrm{m}^{-3}, \mathrm{D}: 270 \mathrm{~kg} \cdot \mathrm{m}^{-3}\right)$ and after sintering at $950{ }^{\circ} \mathrm{C}(\mathrm{A}$ : $\left.500 \mathrm{~kg} \cdot \mathrm{m}^{-3}, B: 370 \mathrm{~kg} \cdot \mathrm{m}^{-3}, C: 310 \mathrm{~kg} \cdot \mathrm{m}^{-3}, \mathrm{D}: 260 \mathrm{~kg} \cdot \mathrm{m}^{-3}\right)$.

Foams labelled A (solid and ceramic, with a density of $500 \mathrm{~kg} \cdot \mathrm{m}^{-3}$ ) had smaller pores and thicker walls than foams B, C and D (with lower densities ranging from 260 to $370 \mathrm{~kg} \cdot \mathrm{m}^{-3}$ ). More precisely, the lower the density, the larger the pore size and the finer the walls (more details in section 3.1.2 and Figure 7). Nevertheless, the wall structure of all the foams we examined appeared to be very similar irrespective of the porosity level.

In the sintering step, slight shrinkage was observed with a few distortions of the pores. Apart from this, wall porosity did not change, and no evidence of sintering or melting of pore walls leading to porosity losses was observed.

Shrinkage during the sintering step was evaluated in the SEM images (magnification x100) using Meshpore software. The results are summarised in Table 1. All the samples examined exhibited shrinkage values $<5 \%$, and most were $<2 \%$. Local shrinkage appears to be independent of both density and direction ( $X$ and $Y$ axes).

Table 1: X and Y-axis shrinkage in absolute values of SEM foam using Meshpore software

\begin{tabular}{|c|c|c|c|}
\hline \multirow{2}{*}{ Foam } & Density (kg.m²) & \multirow{2}{*}{$\begin{array}{c}X \text {-Axis shrinkage } \\
(\%)\end{array}$} & \multirow{2}{*}{$\begin{array}{c}Y \text {-Axis shrinkage } \\
(\%)\end{array}$} \\
\hline & Before After & & \\
\hline
\end{tabular}




\section{Journal Pre-proof}

\begin{tabular}{ccccc}
\hline & sintering & sintering & & \\
\hline & & & 1.37 & 3.75 \\
$\mathrm{~A}$ & 500 & 500 & 0.91 & 1.43 \\
& & & 1.88 & 1.64 \\
\hline \multirow{2}{*}{$\mathrm{B}$} & \multirow{2}{*}{370} & \multirow{2}{*}{370} & 1.74 & 0.75 \\
& & & 0.57 & 1.30 \\
\hline $\mathrm{C}$ & \multirow{2}{*}{320} & 310 & 3.68 & 2.89 \\
\hline $\mathrm{D}$ & 270 & 260 & 2.03 & 0.67 \\
\hline
\end{tabular}

\subsubsection{X-ray Tomography}

$\mu$-CT made it possible to analyse samples in 3D, and to quantify 2,500 objects (counted as pores) inside $402 \mathrm{~mm}^{3}$ (foam D) to more than 7,200 objects (pores) inside $328 \mathrm{~mm}^{3}$ (foam A) (Figure 7).

At 9- $\mu$ m voxel size, the pore fraction was found to be connected (> 99\%) in all samples. At this voxel size, some walls could not be detected at all, and the dimensions of some were $<5$ $\mu \mathrm{m}$ in the SEM images (Figure 5) or on nano-CT images at 1- $\mu \mathrm{m}$ voxel size (Figure 6).

Wall porosity was visible at $1-\mu \mathrm{m}$ voxel size, and could be estimated. For foam $\mathrm{C}$, the volume fraction of the wall was $13 \%$ for solid foam and $11.7 \%$ for ceramic foam. At $9-\mu \mathrm{m}$ voxel size, the volume fraction of the wall was $21.5 \%$ in both solid and ceramic foam $\mathrm{C}$. The density of foam $\mathrm{C}$ was measured experimentally and the results were compared to theoretical calculation using equation (5) :

$$
\boldsymbol{\rho}=\left(\mathbf{1}-\boldsymbol{\Phi}_{t}\right) * \boldsymbol{\rho}_{\boldsymbol{d}}
$$

where $\rho$ is the theoretical density of the foam, $\rho_{d}$ the density of the solid without porosity and $\Phi_{t}$ the total porosity. Both methods produced very similar results, with differences $<15 \mathrm{~kg} . \mathrm{m}^{-3}$ for solid and ceramic foams.
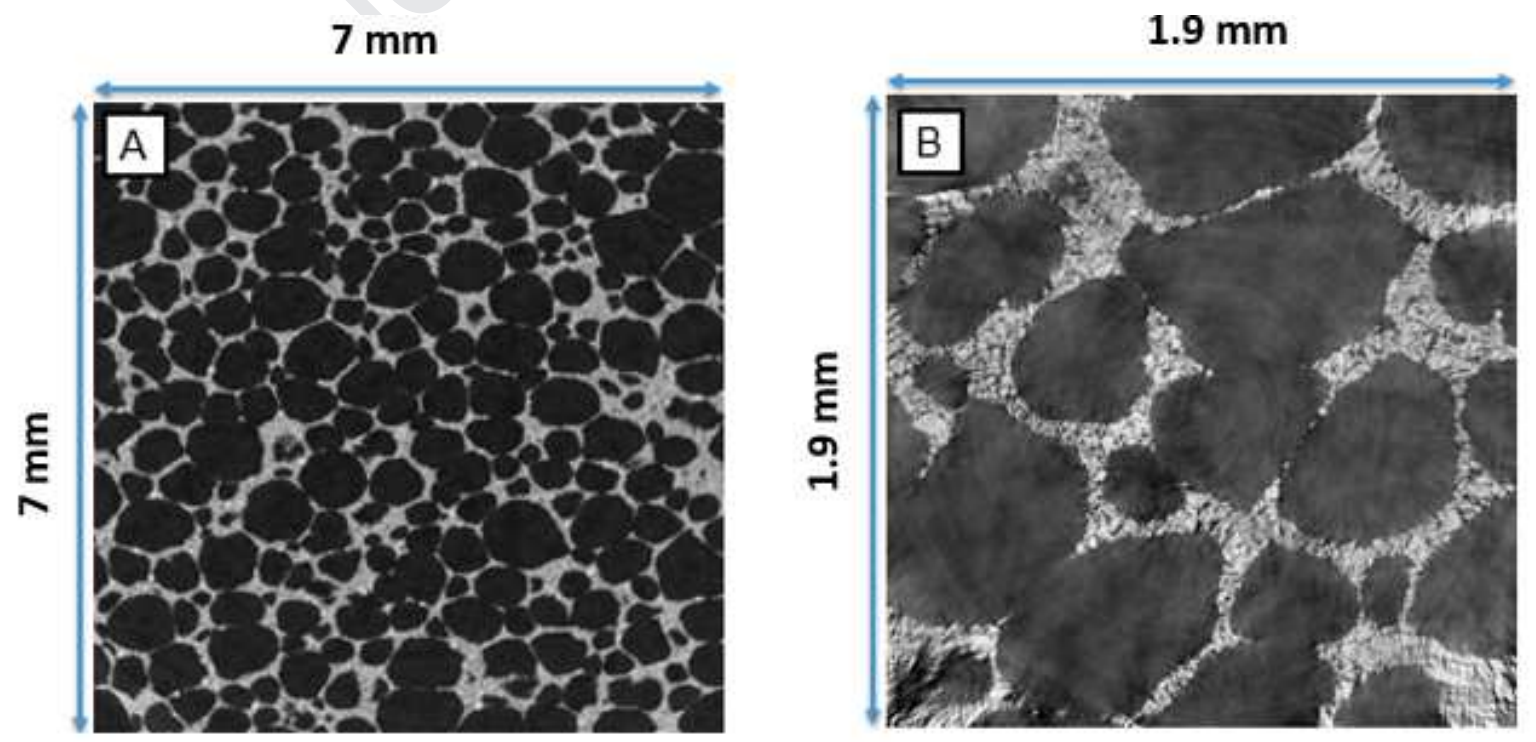


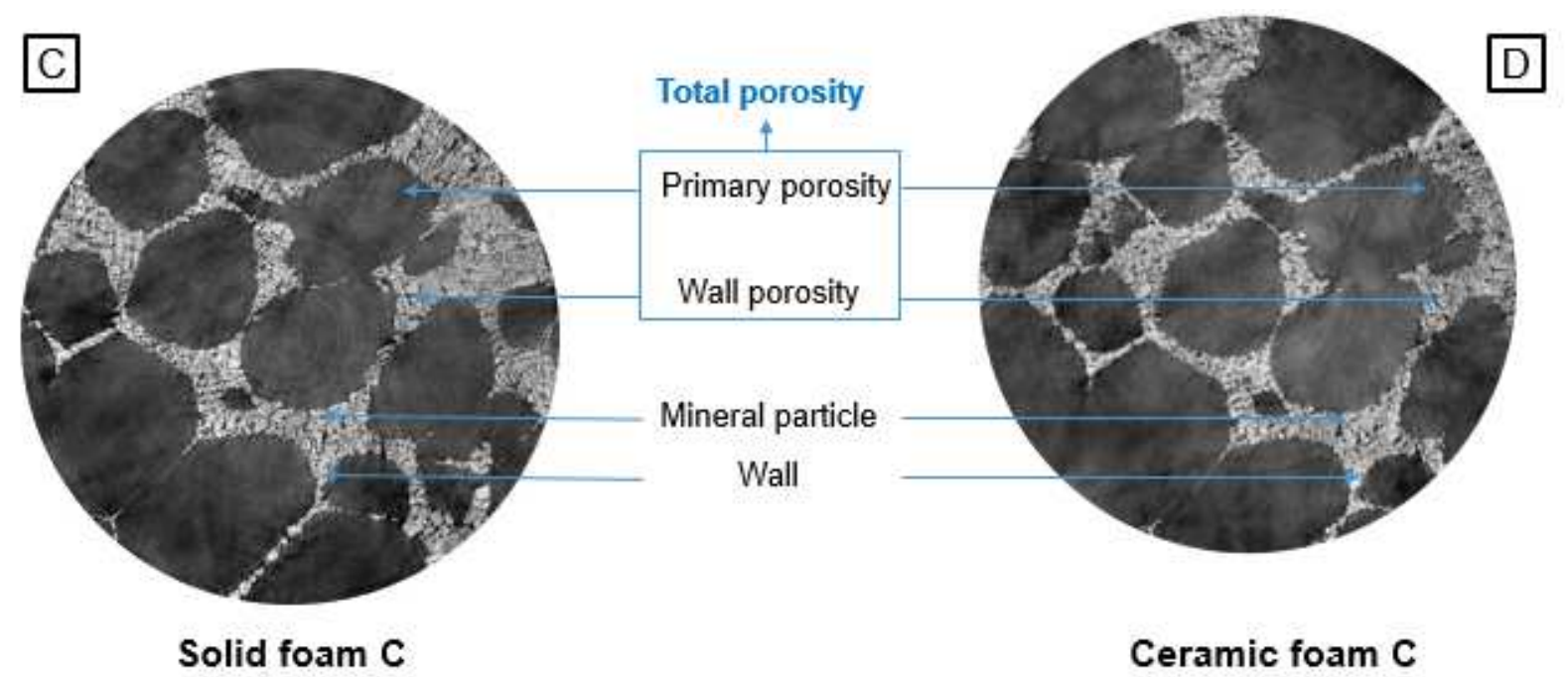

Figure 6: Slices of foam $C$ obtained using tomography and XAct $2 \bowtie$ software under different conditions: (A) one slice of

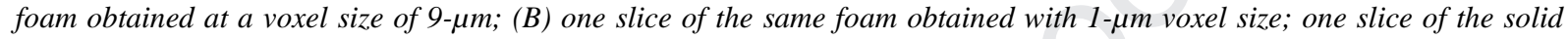
foam before sintering $(C)$ and after sintering $(D)$ at 1- $\mu \mathrm{m}$ voxel size. $(B)$ and $(D)$ are two slices from the same analysis of ceramic foam.

Wall porosity was determined using two hypotheses. First, the fraction of total $\left(\Phi_{t}\right)$ porosity was satisfactorily estimated from nano-CT analysis at $1-\mu \mathrm{m}$ voxel size. Second, total porosity was the sum of primary $\left(\Phi_{p}\right)$ and wall porosity $\left(\Phi_{w}\right)$. Based on these considerations, wall porosity was estimated as follows:

$$
\Phi_{w}=\Phi_{t}-\Phi_{p}=1-\frac{\rho^{*}}{\rho_{d}}-\Phi_{p}
$$

where $\rho^{*}$ is the apparent density of the foam and $\rho_{d}$ the density of the solid without porosity.

Estimated wall porosity values are summarized in Table 2. Two methods were used to estimate $\Phi_{w}$ using equation (6). Method 1 was applied to all foam samples using measured $\rho^{*}$ and $\rho_{d}$, and $\Phi_{p}$ found with $\mu$-CT analysis, whereas method 2 was applied to foam C using $\Phi_{t}$ found with nano-CT analysis and the same $\Phi_{p}$ used in method 1 . For solid foam C, for example, it represented $9 \%$ and $8.5 \%$ of the total volume fraction of the foam with method 1 and 2 , respectively.

The walls were porous and were composed of about $40 \%$ porosity. The proportion of porosity inside the wall (i.e. the estimated ratio of $\Phi_{w}$ of foam to the volume fraction of the walls) increased with density from $37 \%$ to $42 \%$ and from $41 \%$ to $47 \%$ in the solid and ceramic foams, respectively. It therefore appears that the sintering step also had an impact on this ratio.

Table 2: Summary of the volume fraction of the foams. The data obtained by experimental tomography analysis are in bold. Two values are given for foam $C$, both found with equation (6), but the first using estimated $\Phi_{t}$ from method 1 , and the second (in bold) using estimated $\Phi_{t}$ from method 2.

\begin{tabular}{|c|c|c|c|c|c|}
\hline Foam & $\begin{array}{c}\Phi_{\mathbf{p}} \\
(\%)\end{array}$ & $\begin{array}{c}\Phi_{w} \text { of } \\
\text { foam } \\
(\%)\end{array}$ & $\begin{array}{c}\Phi_{\mathrm{t}} \\
(\boldsymbol{\%})\end{array}$ & $\begin{array}{c}\text { Volume } \\
\text { fraction of } \\
\text { wall (\%) }\end{array}$ & $\begin{array}{c}\text { Porosity } \\
\text { proportion } \\
\text { inside the wall } \\
(\%)\end{array}$ \\
\hline
\end{tabular}




\begin{tabular}{|c|c|c|c|c|c|c|c|c|c|}
\hline \multirow{4}{*}{$\begin{array}{l}\text { Solid } \\
\text { foam }\end{array}$} & A & 69.2* & \multicolumn{2}{|c|}{11.3} & \multicolumn{2}{|c|}{80.5} & $30.8 *$ & \multicolumn{2}{|c|}{37} \\
\hline & B & $76.1 *$ & \multicolumn{2}{|c|}{9.4} & \multicolumn{2}{|c|}{85.5} & $23.9 *$ & \multicolumn{2}{|c|}{39} \\
\hline & $\mathrm{C}$ & $78.5^{*}$ & 9 & 8.5 & 87.5 & $87 * *$ & $21.5 *$ & 42 & 40 \\
\hline & D & $82 *$ & \multicolumn{2}{|c|}{7.5} & \multicolumn{2}{|c|}{89.5} & $18 *$ & \multicolumn{2}{|c|}{42} \\
\hline \multirow{4}{*}{$\begin{array}{c}\text { Ceramic } \\
\text { foam }\end{array}$} & A & $67.2 *$ & \multicolumn{2}{|c|}{13.3} & \multicolumn{2}{|c|}{80.5} & $32.8 *$ & \multicolumn{2}{|c|}{41} \\
\hline & B & $76.9 *$ & \multicolumn{2}{|c|}{8.6} & \multicolumn{2}{|c|}{85.5} & $23.1 *$ & \multicolumn{2}{|c|}{37} \\
\hline & $\mathrm{C}$ & $78.5^{*}$ & 9.4 & 9.8 & 87.9 & $88.3 * *$ & $21.5 *$ & 44 & 46 \\
\hline & D & $80.9 *$ & \multicolumn{2}{|c|}{8.9} & \multicolumn{2}{|c|}{89.8} & $19.1 *$ & \multicolumn{2}{|c|}{47} \\
\hline
\end{tabular}

* obtained with $9-\mu \mathrm{m}$ voxel size using $\mu$-CT

** obtained with $1-\mu \mathrm{m}$ voxel size using nano-CT

Figure 7 shows the cumulative volume fractions of the pores plotted as a function of equivalent spherical pore diameters for foams of different porosities before and after sintering. Ceramic foams had the same pore distributions as their solid foam counterparts. In both cases, the denser the foam, the smaller and the more numerous the pores.
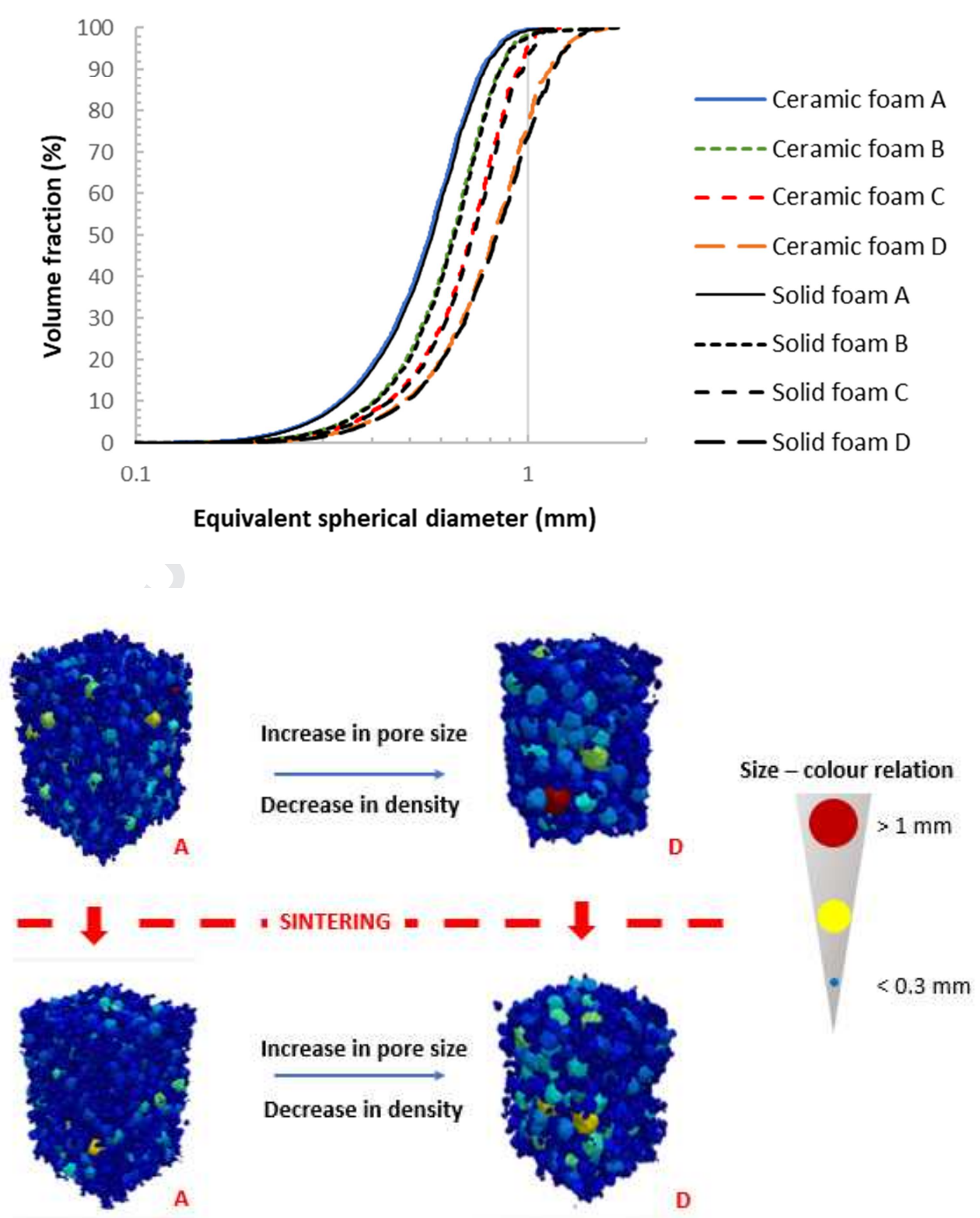
Figure 7: The graph at the top of the figure shows pore size distribution of solid (in black) and ceramic foam (in colour) with the smallest pores having equivalent spherical diameter in the order of $10^{-4} \mathrm{~mm}$. The two bottom rows show reconstructed foam $3 D$ pore structures (without wall mask) obtained with Simpleware ScanIP ${ }^{T M}$ software. Foam A and D are represented before and after sintering.

Table 3 list the characteristic values of pore size distribution in the foams. In solid foams, $10 \%$ of total volume fraction had equivalent spherical diameters $<0.340 \mathrm{~mm}$ for foam $\mathrm{A}$, and $<0.490 \mathrm{~mm}$ for foam $\mathrm{D}$. This ratio of 1.45 did not change much for $\mathrm{D}_{50}$ and $\mathrm{D}_{90}$ with values of 1.45 and 1.49 respectively. There was also an increasing trend in comparison with $\mathrm{B}$ and $\mathrm{C}$ foams. There was a 1.44, 1.45, 1.49 increase between ceramic foam A and ceramic foam D for $\mathrm{D}_{10}, \mathrm{D}_{50}$ and $\mathrm{D}_{90}$.

The span of the size distribution is defined as follows:

$$
\operatorname{span}=\frac{D_{90}-D_{10}}{D_{50}}
$$

Span values for solid and ceramic foams were low and similar, ranging from 0.7 to $0.8 \mathrm{~mm}$. Generally, the smaller the span, the more homogeneous the pore size and the more stable the foam (Cantat et al. [35]).

Table 3: Pore size distribution of solid and ceramic foam samples. $D_{10}, D_{50}$ and $D_{90}$ correspond to respectively $10 \%, 50 \%$ and $90 \%$ of pore volume fraction with a diameter below the given value. For example, $D_{10}=0.4 \mathrm{~mm}$ means that $10 \%$ of volume fraction of pores had an equivalent spherical diameter $<0.4 \mathrm{~mm}$.

\begin{tabular}{cccccc}
\hline Foam & & $\mathbf{D}_{\mathbf{1 0}}(\mathbf{m m})$ & $\mathbf{D}_{\mathbf{5 0}}(\mathbf{m m})$ & $\mathbf{D}_{\mathbf{9 0}}(\mathbf{m m})$ & span \\
\hline \multirow{5}{*}{ Solid foam } & A & 0.341 & 0.573 & 0.778 & 0.8 \\
& B & 0.410 & 0.651 & 0.848 & 0.7 \\
& C & 0.446 & 0.724 & 0.971 & 0.7 \\
& D & 0.490 & 0.832 & 1.163 & 0.8 \\
\hline \multirow{2}{*}{ Ceramic foam } & A & 0.333 & 0.562 & 0.763 & 0.8 \\
& B & 0.405 & 0.643 & 0.852 & 0.7 \\
& C & 0.442 & 0.720 & 0.946 & 0.7 \\
& D & 0.480 & 0.817 & 1.134 & 0.8 \\
\hline
\end{tabular}

3.2. Mechanical properties

3.2.1. Compression

The crushing strength of the foams was investigated and compared to that of commercial samples (Figure 8). The crushing strength $\sigma^{*}$ increased with density and after sintering. Ceramic foams exhibited very high $\sigma^{*}$ values, up to 3 times higher than those measured on solid foams for the highest densities $\left(500 \mathrm{~kg} \cdot \mathrm{m}^{-3}\right)$. For lighter foams $\left(250 \mathrm{~kg} \cdot \mathrm{m}^{-3}\right.$ in density), $\sigma^{*}$ was $<1 \mathrm{MPa}$ for both solid and ceramic foams. Hence, the higher the density, the bigger the difference between the compressive strength of solid and ceramic foams. Considering that sintering had no effect on foam density, the increase in compressive strength cannot be explained by a change in porosity. Table 4 illustrates these behaviours in ceramic and solid foam, with significant differences in compressive strength for foams $\mathrm{A}$ and $\mathrm{B}$, whereas there was no significant difference in $\mathrm{C}$ and $\mathrm{D}$.

At the same density, values measured on light brick were slightly lower than those measured on solid foam and much lower than those measured on ceramic foam. No significant difference in $\sigma^{*}$ was found between light brick, ceramic foams $\mathrm{C}$ and $\mathrm{D}$, and solid foams $\mathrm{B}$ 
and C. It is therefore possible to use porous insulation materials that are lighter than brick but have the same mechanical properties in compression.

Ultra-light concrete was lighter than all the other materials tested and $\sigma^{*}$ values were thus weaker. Based on Figure 8, it is likely that if the density of solid and ceramic foams could be reduced to values close to those of ultra-light concrete, their mechanical behaviour would probably be very similar to their own, with a very light material well suited for insulation.

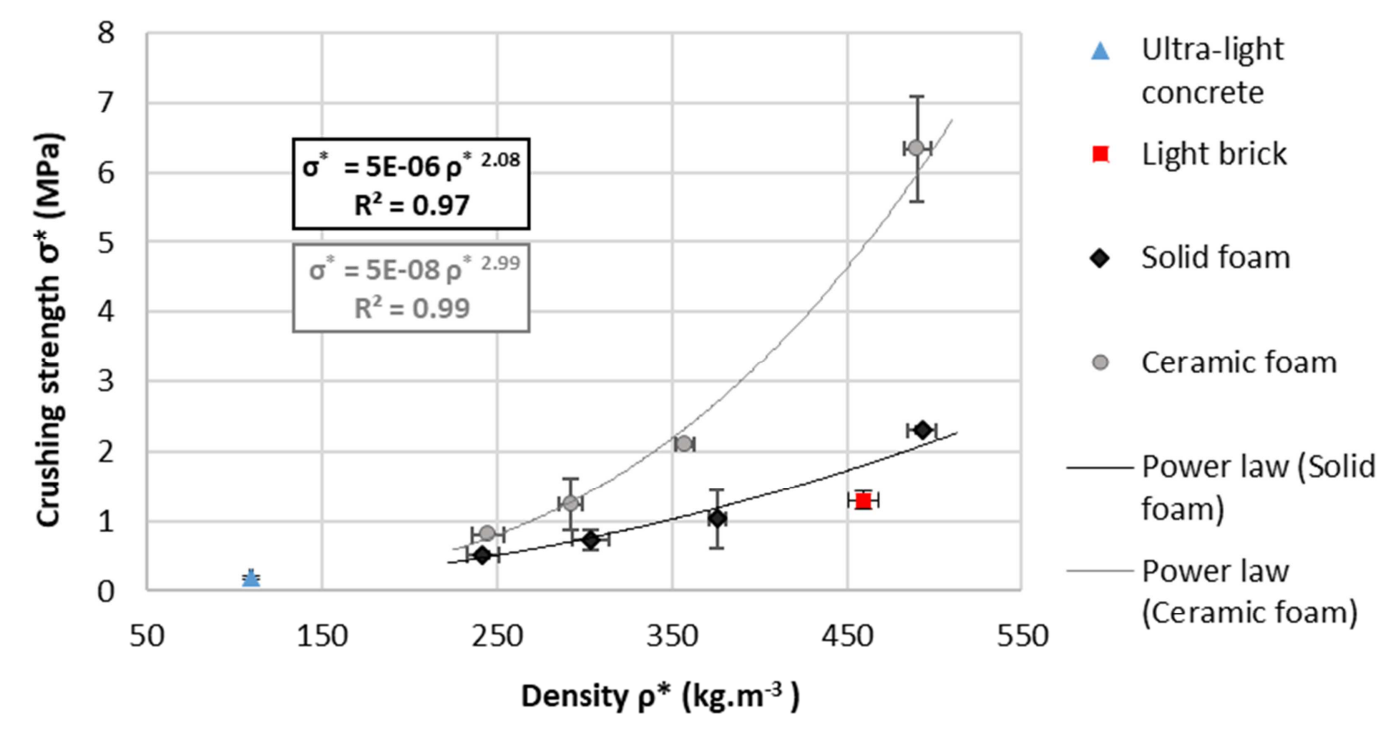

Figure 8: Crushing strength vs density of solid foam, ceramic foam, and commercial porous materials: light brick and ultralight concrete, using equation (8) for solid and ceramic foams. Power law model values are in grey for ceramic foam and in black for solid foam. Average experimental values for commercial porous material were $0.201 \mathrm{MPa}$ for $110 \mathrm{~kg} . \mathrm{m}^{-3}$ (ultralight concrete) and $1.32 \mathrm{MPa}$ for $459 \mathrm{~kg} \cdot \mathrm{m}^{-3}$ (light brick).

Power law models according to equation (8) were fitted to experimental data for both ceramic and solid foams (Figure 8):

$$
\boldsymbol{\sigma}^{*}=\boldsymbol{A} \boldsymbol{\rho}^{* n}
$$

where $\sigma^{*}$ and $\rho^{*}$ are the crushing strength and the density of the foam, respectively, and $A$ and $n$ are two constants.

Crushing strength of solid foams evolved almost like the square of the density $(n=2.17)$ whereas values of ceramic foam evolved with almost the cube of the density $(n=2.99)$. This reflects the higher dependence of fracture properties on density in ceramic materials. At the lowest densities, the properties of the two materials are more similar. The same observation also applies to the mechanical properties of commercial porous materials. Light brick was fitted, with medium correlation, to solid foam values. By extrapolation of the power law model (Figure 8), ultra-light concrete was fitted to either solid or ceramic foam values.

In the literature, many studies used specific models based on Gibson and Ashby [24] to predict mechanical properties with respect to the overall structure of a cellular solid. For open-cell materials, the model is based on a unit cell composed of an open pore surrounded by walls represented by a cubic array of struts of square cross section and length. For compressive behaviour of brittle foam materials, the authors proposed the following relation between crushing strength and density: 


$$
\frac{\sigma^{*}}{\sigma_{s}}=C\left(\frac{\rho^{*}}{\rho_{s}}\right)^{\alpha}
$$

where $\sigma^{*} / \sigma_{s}$ is the relative crushing strength defined as crushing strength of material normalised by theoretical crushing strength of the solid counterpart (the wall), $\rho * / \rho_{s}$, the relative density defined as the apparent density of material normalised by density of the wall, $C$ and $\alpha$, two constants depending on geometry and size of the pores of the cellular material.

According to Gibson and Ashby [24], foams with fracture dominant behaviour and open-cell structures have $C$ and $\alpha$ values of 0.2 and 3/2, respectively, leading to the following equation :

$$
\frac{\sigma^{*}}{\sigma_{s}}=0.2\left(\frac{\rho^{*}}{\rho_{s}}\right)^{\frac{3}{2}}
$$

Wall properties cannot be accessed experimentally. The theoretical density of the wall $\rho_{s}$ was estimated from a volume balance of the ingredients of the non-aerated suspension equal to $1600 \mathrm{~kg} \cdot \mathrm{m}^{-3}$. The crushing strength of wall material $\sigma_{s}$ was then estimated using equation (10). An average value of $\sigma_{s}$ equal to $52 \mathrm{MPa}$ and $108 \mathrm{MPa}$ was found for solid foams and ceramic foams A, B, C and D, respectively.

Figure 9 shows relative crushing strength vs the relative density of the solid and ceramic foams, highlighting the fact that the Gibson and Ashby equation fitted measurements of the present foams in the range of the values studied. The fit was relatively good for solid foams $\left(r^{2}=0.94\right)$, but less good for the ceramic ones $\left(r^{2}=0.72\right)$, with only one of the four average values closely fitting the model. The model overestimates the crushing strength values for low density, and conversely, the experimental values are higher for denser samples.

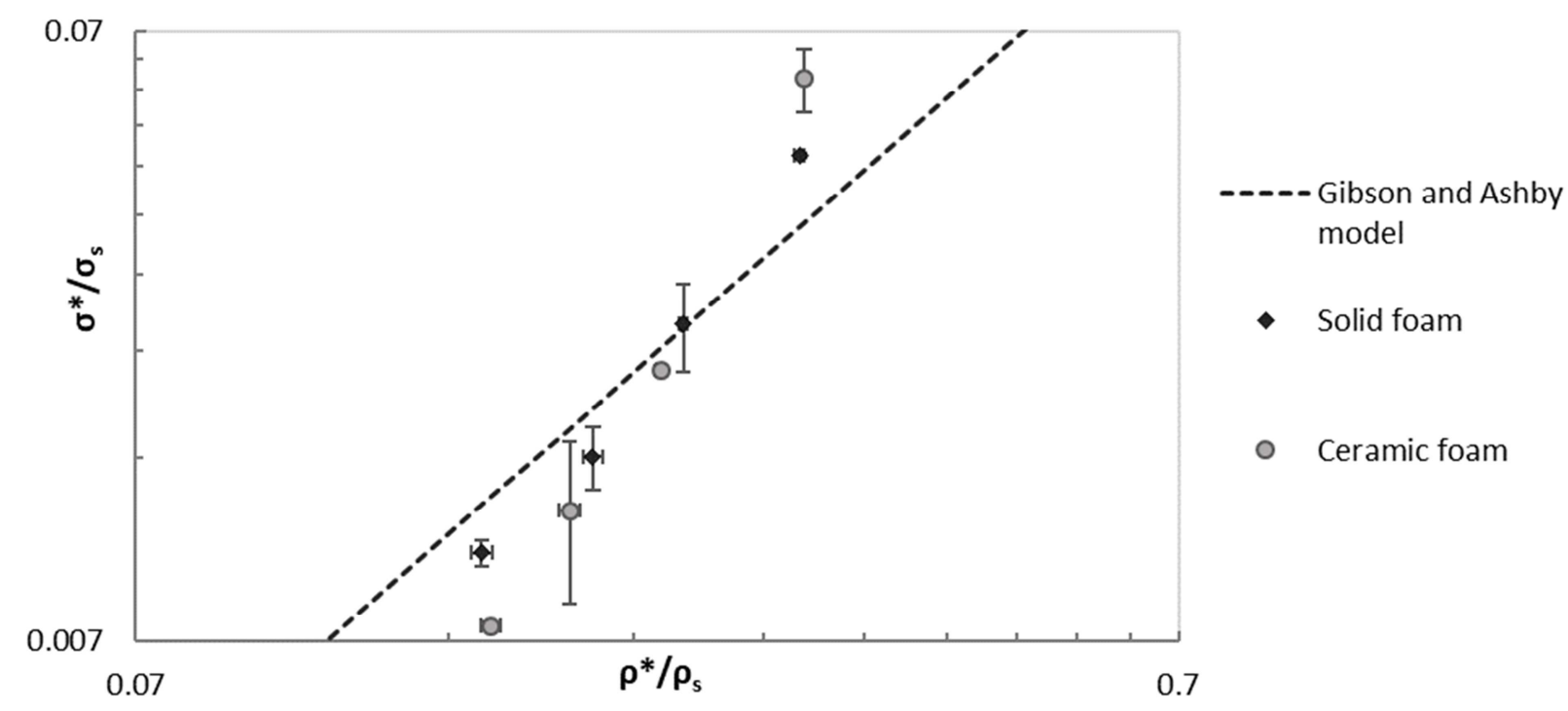

Figure 9: Relative crushing strength vs relative density of solid and ceramic foam using the Gibson and Ashby model.

An adjusted power law model of the same form as Gibson and Ashby (equation (9), was used to better fit the experimental data, with $C$ and $\alpha$ values of 0.55 and 2.17 for solid foams, and 1.9 and 2.99 for ceramic foams $\left(r^{2}=0.99\right)$. The slope was steeper than those proposed by Gibson and Ashby. 


\subsubsection{Bending properties}

Figure 10 presents a plot of Young modulus $\left(E^{*}\right)$ vs foam density $\left(\rho^{*}\right)$. Slightly higher $E^{*}$ values were found for ceramic foams, but they did not significantly differ from those measured on solid foams (Table 4). Hence, sintering had no effect on the $E^{*}$.

A power law model based on equation (11) was adjusted to solid and ceramic $E^{*}$ experimental values (Figure 10):

$$
\boldsymbol{E}^{*}=\boldsymbol{A}^{\prime} \boldsymbol{\rho}^{* \boldsymbol{n}}
$$

where $A^{\prime}$ and $n^{\prime}$ are two constants of the power law model.

Young modulus $E^{*}$ of the solid and ceramic foams increased with almost the square of $\rho^{*}$ in the range of studied values, where $n^{\prime}=2.14$ for solid foam and $n^{\prime}=1.80$ for ceramic foams.

$E^{*}$ of ultra-light concrete was $84 \pm 8 \mathrm{MPa}$ for a density of $100 \pm 1 \mathrm{~kg} \cdot \mathrm{m}^{-3}$. This $E^{*}$, appeared to behave similarly in solid and ceramic foams by extrapolation of power law model (Figure 10). For the present range of low densities, the properties of the matrix of this material would be of the same order of magnitude as that of our materials.

No measurement of light bricks was possible as the material is too brittle and very sensitive to slight deformation in tension.

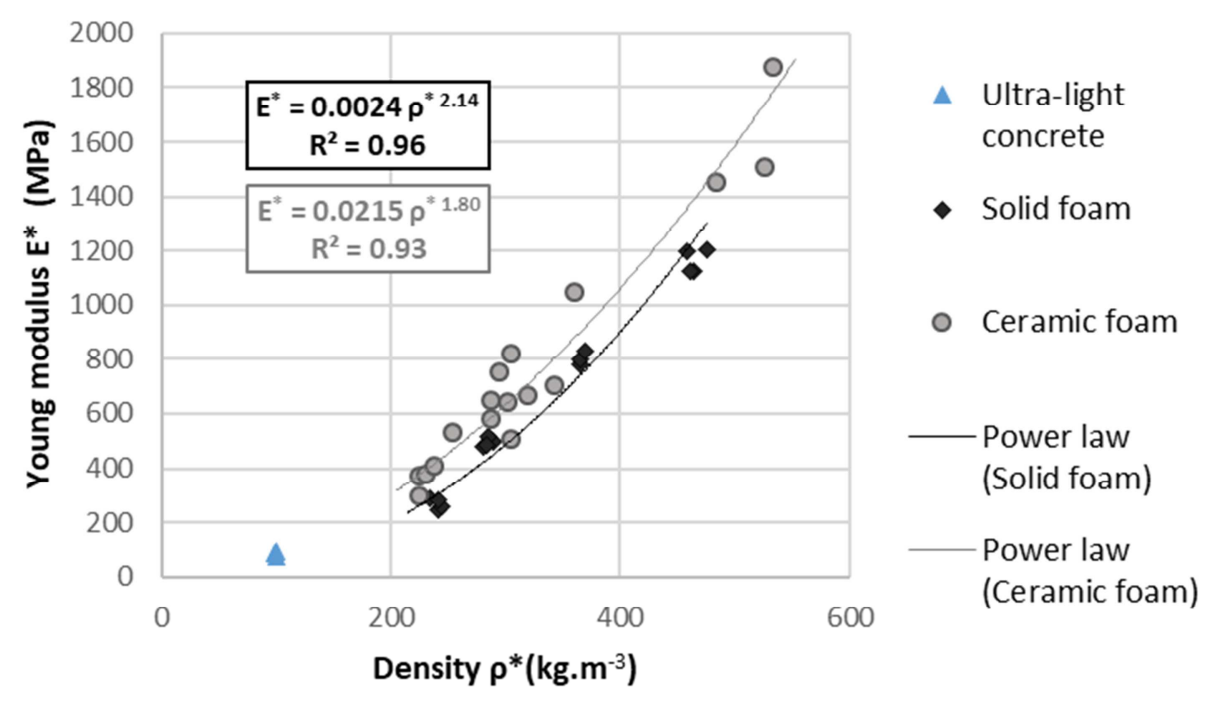

Figure 10: Young modulus of ultra-light concrete, ceramic foam and solid foam vs density using the power law model from equation (11). Power law model values are in grey for ceramic foam and in black for solid foam. 


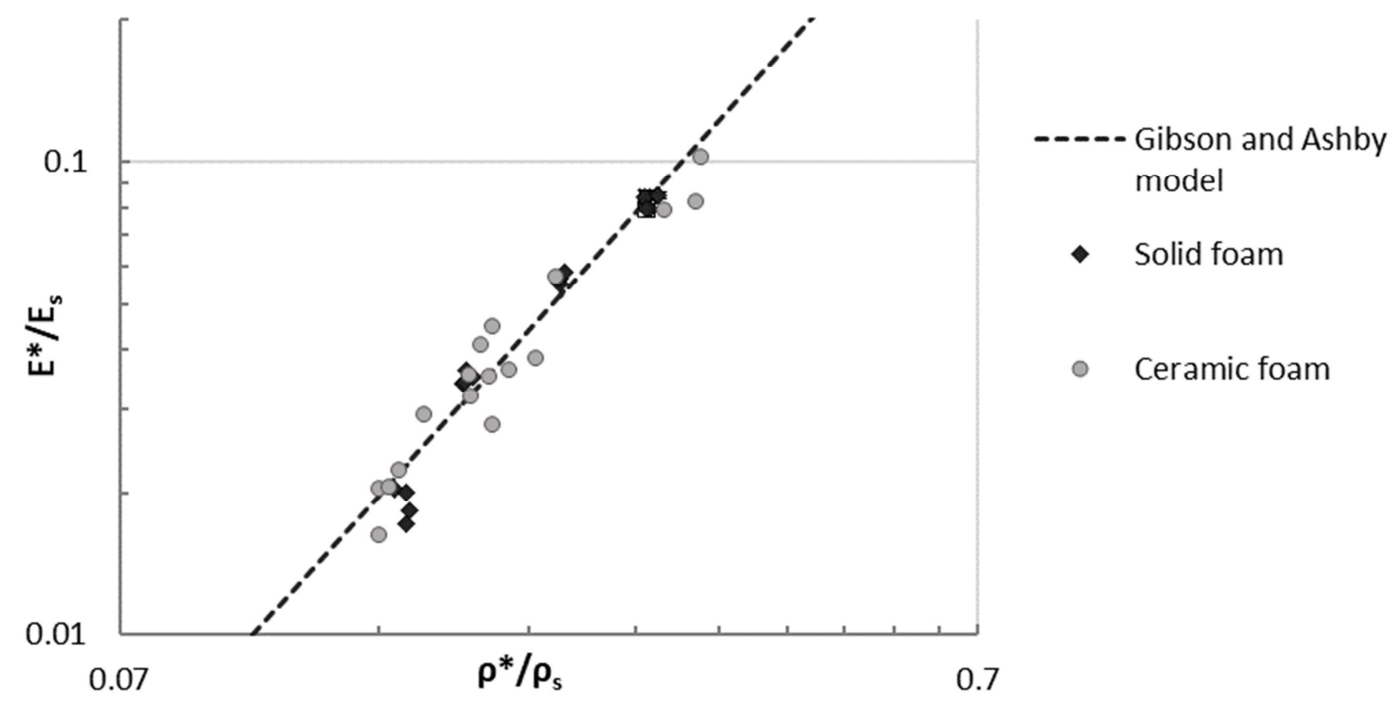

Figure 11: Relative Young modulus vs relative density using the Gibson and Ashby model on solid and ceramic foam.

Like for the compression tests, a Gibson and Ashby model was expressed using the following equation:

$$
\frac{E^{*}}{E_{s}}=C^{\prime}\left(\frac{\rho^{*}}{\rho_{s}}\right)^{\beta}
$$

where $E^{*}$ and $E_{s}$ are the apparent Young modulus of material measured in flexion and the theoretical Young modulus of the wall material, respectively, $\rho^{*}$ and $\rho_{s}$, the apparent density of material and the density of the solid counterpart, respectively, $C^{\prime}$ and $\beta$ are two constants that provide information on the topology and deformation mechanism of the cell material (Ashby [36]).

According to Gibson and Ashby [24], $C^{\prime}$ and $\beta$ are equal to 1 and 2, respectively, for brittle open-cell foams, leading to this expression :

$$
\frac{E^{*}}{E_{s}}=\mathbf{1}\left(\frac{\rho^{*}}{\rho_{s}}\right)^{2}
$$

Equation (13) was applied with $\rho_{s}=1600 \mathrm{~kg} \cdot \mathrm{m}^{-3}$ to estimate the $E_{s}$ of foams A, B, C and D, and average $E_{s}$ values of 14,200 and $18,400 \mathrm{MPa}$ were found for solid foam and ceramic foam, respectively. Young modulus measured in flexion for solid foams satisfactorily fitted the Gibson and Ashby equation for solid foams $\left(r^{2}=0.99\right)$ and ceramic foam $\left(r^{2}=0.97\right)$.

Values of $E^{*}$ for a low density of $110 \mathrm{~kg} \cdot \mathrm{m}^{-3}$ were estimated using $E_{s}$ calculated for foams with equation (13), and were $67 \mathrm{MPa}$ and $87 \mathrm{MPa}$ for solid and ceramic foam, respectively. These values are lower than those found for ultra-light concrete (Table 4) and for solid foam and similar to values found for ceramic foam.

For more dense materials like concrete, Ashby and Jones [37] published Young modulus data which ranged between 20,000 and $40,000 \mathrm{MPa}$ for densities ranging from 2,200 to 2,500 $\mathrm{kg} \cdot \mathrm{m}^{-3}$. These values are in agreement with the results found for solid and ceramic foams for $\mathrm{E}_{\mathrm{s}}\left(14,200\right.$ and $18,400 \mathrm{MPa}$ for solid and ceramic foam, respectively) and $\rho_{\mathrm{s}}\left(1,600 \mathrm{~kg} \cdot \mathrm{m}^{-3}\right)$. 
Flexural strength $F_{m}$ also increased with an increase in the density of the materials (Figure 12), like all the mechanical properties tested is this study. This type of foam is more sensitive to tensile fracture than compression and thus bending failure will spread easily and damage the material (Belrhiti et al. [38]; Scheffler and Colombo [11]).

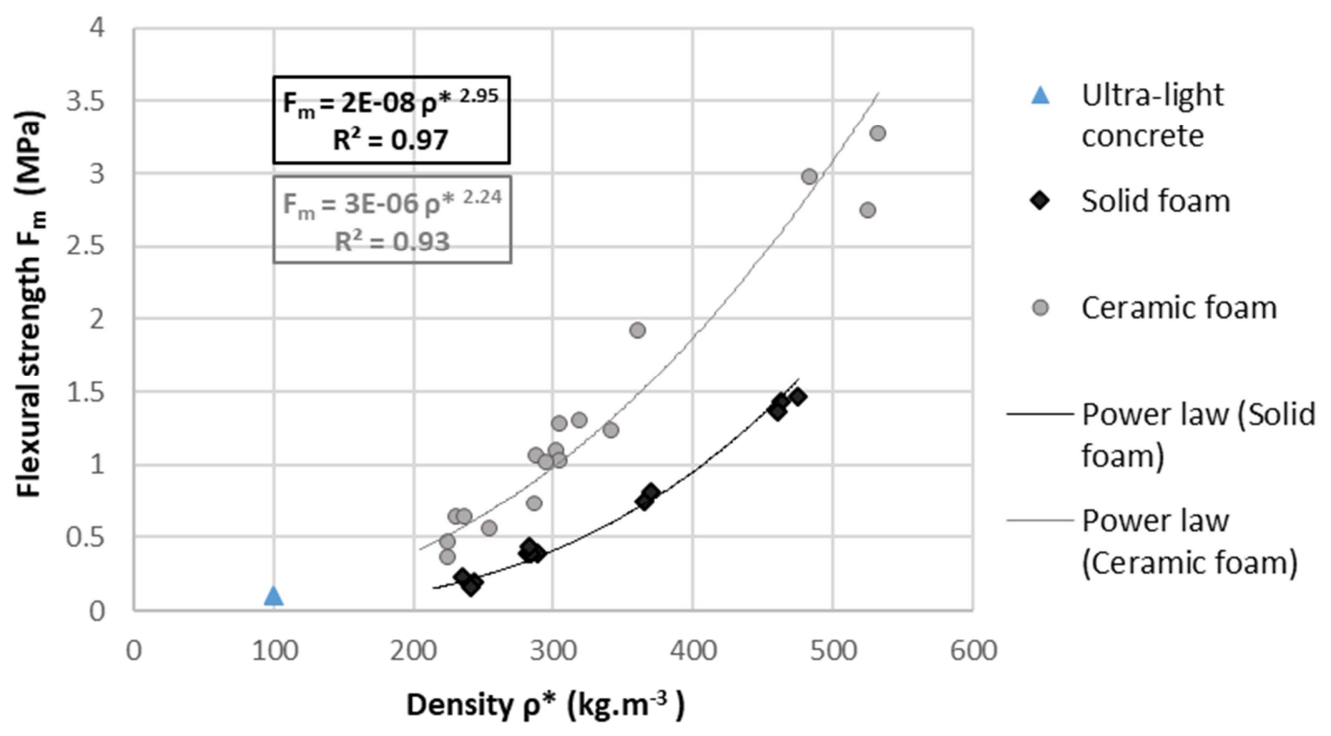

Figure 12: Flexural strength of materials vs density using power law model. Power law model values are represented in grey for ceramic foam and in black for solid foam.

The difference in $F_{m}$ between solid and ceramic foams A, B, C and D was significant, despite the fact the density of the ceramic foams (except for ceramic foam A) was significantly lower. The flexural strength of the solid foam was weaker than that of the ceramic foams; for a density value of $500 \mathrm{~kg} \cdot \mathrm{m}^{-3}$, the bending strength value of solid foams will be half as high. Hence, the denser the material, the bigger the difference in $F_{m}$.

Equation (14) was used to fit experimental data on solid and ceramic foam $F_{m}$ :

$$
F_{m}=A^{\prime \prime} \rho^{* n "}
$$

where $A$ " and $n$ " are constants of the power law model.

Experimental values of $F_{m}$ and density of ceramic and solid foams fitted the power law model well. Like compressive strength, $F_{m}$ values of ceramic foam evolved like the square of foam density $(n ”=2.24)$ and like the cube of foam density $(n ”=2.95)$ for solid foam.

$F_{m}$ of ultra-light concrete was $0.101 \pm 0.005 \mathrm{MPa}$, revealing no significant difference in $F_{m}$ between ultra-light concrete, solid foam $\mathrm{C}$ and $\mathrm{D}$, and ceramic foam $\mathrm{D}$. For these materials, the lighter the material, the smaller the $F_{m}$ gap.

According to these considerations, if the density of the foam materials were reduced to 100 $\mathrm{kg} \cdot \mathrm{m}^{-3}$ (ultra-light concrete density), $F_{m}$ values would probably be close to the average value of the ultra-light concrete. 
Table 4: Mechanical properties of the materials*

\begin{tabular}{|c|c|c|c|c|c|}
\hline \multirow{2}{*}{ Materials } & \multicolumn{2}{|c|}{ Compression test } & \multicolumn{3}{|c|}{ 3-point bending test } \\
\hline & $\rho^{*}\left(\mathrm{~kg} \cdot \mathrm{m}^{-3}\right)$ & $\sigma^{*}(\mathbf{M P a})$ & $\rho^{*}\left(\mathbf{k g} \cdot \mathbf{m}^{-3}\right)$ & $E^{*}(\mathbf{M P a})$ & $F_{m}(\mathrm{MPa})$ \\
\hline $\begin{array}{l}\text { Ultra-light } \\
\text { concrete }\end{array}$ & $110 \pm 1^{\mathrm{a}}$ & $\begin{array}{c}0.201 \pm \\
0.024^{\mathrm{a}}\end{array}$ & $100 \pm 1^{\mathrm{a}}$ & $84 \pm 8^{\mathrm{a}}$ & $\begin{array}{c}0.101 \pm \\
0.005^{\mathrm{a}}\end{array}$ \\
\hline Light brick & $459 \pm 8^{\mathrm{e}}$ & $\begin{array}{c}1.32 \pm \\
0.13^{\mathrm{c}}\end{array}$ & ( & - & - \\
\hline Solid foam A & $486 \pm 5^{\mathrm{f}}$ & $\begin{array}{c}2.297 \pm \\
0.048^{\mathrm{d}}\end{array}$ & $465 \pm 6^{\mathrm{e}}$ & $1163 \pm 38^{\mathrm{e}}$ & $\begin{array}{l}1.41 \pm \\
0.04^{\mathrm{d}}\end{array}$ \\
\hline Solid foam B & $375 \pm 6^{\mathrm{d}}$ & $\begin{array}{l}1.22 \pm \\
0.39^{\mathrm{bc}}\end{array}$ & $367 \pm 2^{d}$ & $804 \pm 20^{\mathrm{d}}$ & $\begin{array}{l}0.77 \pm \\
0.03^{\mathrm{bc}}\end{array}$ \\
\hline Solid foam C & $308 \pm 12^{c}$ & $\begin{array}{l}0.74 \pm \\
0.14^{\text {abc }}\end{array}$ & $284 \pm 3^{c}$ & $495 \pm 13^{b c}$ & $\begin{array}{l}0.40 \pm \\
0.02^{\mathrm{ab}}\end{array}$ \\
\hline Solid foam D & $241 \pm 5^{b}$ & $\begin{array}{l}0.512 \pm \\
0.051^{\mathrm{ab}}\end{array}$ & $240 \pm 4^{\mathrm{b}}$ & $269 \pm 19^{\mathrm{ab}}$ & $\begin{array}{c}0.19 \pm \\
0.03^{\mathrm{a}}\end{array}$ \\
\hline Ceramic foam A & $494 \pm 4^{f}$ & $\begin{array}{c}6.34 \pm \\
0.75^{\mathrm{e}}\end{array}$ & $514 \pm 22^{f}$ & $1612 \pm 189^{f}$ & $\begin{array}{c}3.00 \pm \\
0.22^{\mathrm{e}}\end{array}$ \\
\hline Ceramic foam B & $357 \pm 3^{\mathrm{d}}$ & $\begin{array}{c}2.108 \pm \\
0.040^{\mathrm{d}}\end{array}$ & $315 \pm 25^{\mathrm{c}}$ & $690 \pm 188^{\mathrm{cd}}$ & $\begin{array}{l}1.33 \pm \\
0.31^{\mathrm{d}}\end{array}$ \\
\hline Ceramic foam $\mathrm{C}$ & $294 \pm 7^{\mathrm{c}}$ & $\begin{array}{l}1.24 \pm \\
0.37^{\mathrm{bc}}\end{array}$ & $307 \pm 21^{\mathrm{c}}$ & $731 \pm 62^{\mathrm{cd}}$ & $\begin{array}{l}1.00 \pm \\
0.18^{\mathrm{cd}}\end{array}$ \\
\hline Ceramic foam D & $246 \pm 6^{\mathrm{b}}$ & $\begin{array}{l}0.804 \pm \\
0.010^{\mathrm{abc}}\end{array}$ & $234 \pm 11^{b}$ & $399 \pm 77^{b}$ & $\begin{array}{l}0.53 \pm \\
0.11^{\mathrm{ab}}\end{array}$ \\
\hline
\end{tabular}

*Values with different superscript letters in the same column are significantly different at $\mathrm{p} \leq 0.05$

Rupture property values ( $\sigma^{*}$ and $F_{m}$ ) also depended on the nature and the cohesion of the wall, and in this study depended more on sintering than $E^{*}$. It was possible to fit all the mechanical values $\left(E^{*}, \sigma^{*}\right.$ and $F_{m}$ obtained in this study with power law models, making the mechanical properties of the foams predictable.

4. Discussion

\subsection{Structure}

A multiscale analysis combining SEM and tomography techniques was used to better understand the mechanisms that create and influence foam structure. The advantage of tomography analysis will also be discussed in this section.

The primary porosity of foam is created during mixing, especially during the foaming step. The greater the quantity of air incorporated, the thinner the liquid matrix around the bubbles. During the drying step, there is competition between thermal expansion of air inclusions and water evaporation which reduces the volume of the matrix. When the binding agent is sufficiently concentrated, the matrix becomes solid and the overall volume can no longer vary. At this point, an open network of pores is generated and evaporation continues, leading to the creation of wall porosity and a larger open network of pores. The formation of pseudo star-shaped cavities was observed in the foams (Figure 13) which could be explained by local demixing leading to separation of the phases between a continuous aqueous phase and mineral 
particles. The aqueous phase then only contains a very small number of mineral particles, and after solidification, the network becomes too weak and falls apart, creating connections between adjacent pores. This phenomenon was also observed by Samson [39] in other mineral foams.

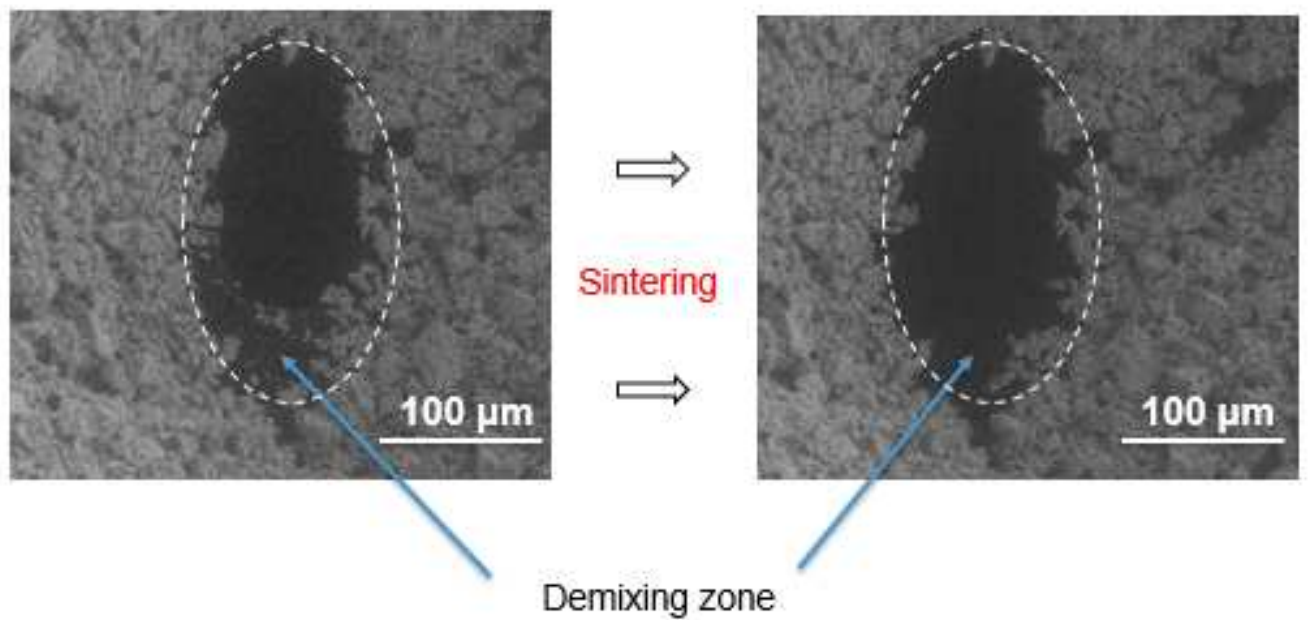

Figure 13: SEM images of a solid mineral foam C before and after sintering, illustrating the formation of a demixing zone in the liquid matrix. This zone was formed after the disappearance of the liquid film deprived sufficient mineral particles and binding agent to form non-porous matrix. This phenomenon leads to interconnection between pores after solidification of the matrix. Inside the white dotted oval, after sintering, it was also possible to see the disappearance of additional weak region.

Solid foams A to D (Figure 2) were dried in the same environment with similar relative humidity and temperature. The expansion of bubbles is driven by heat, and the composition of continuous phase can influence rheological properties (Bey et al. [40]) and increase or reduce heat expansion. According to this hypothesis, the influence of expansion of the bubbles is proportionally equivalent in all foams. Assuming similar drying conditions, evaporation occurred in the same way in all the foams tested, meaning that shrinkage and particle stacking of the continuous phase were comparable. The structure of the wall in Figure 5 supports this hypothesis and wall porosity corresponds to the volume fraction of evaporated water that forms a continuous porous network inside the wall.

The impact of porosity is clearly visible in the SEM images (Figure 5). When the proportion of incorporated air increased, the pores appear to be less spherical, larger, and to have thinner walls. This trend suggested the span value increases with porosity but the experimental values showed no significant change in the span linked to the density of the material (Table 3). Primary porosity decreased with density but remained largely predominant (representing more than $80 \%$ of the total porosity in all the foam samples). In the solid foam resulting from the same initial suspension, wall porosity must still be similar. Combining $\mu$-CT and nano-CT analyses enables full access to porosity even when the wall is less than $9 \mu \mathrm{m}$ thick, which would be impossible with $\mu$-CT analysis alone. Even though wall porosity accounted for only a small amount of total porosity, it still modified the behaviour of the solid foam matrix, increasing open and total porosity with smaller pores than those in primary porosity (the wall pores were smaller than the size of the wall), leading to better thermal properties by reducing thermal conduction in the solid matrix (Glicksam [41]).

The sintering step appeared to have no major effect on foam structure despite some local shrinkage (Table 1) leading to limited matrix damage (Figure 5). The wall porosity did not collapse but remained the same after sintering. In ceramic manufacturing, the aim of the 
sintering step is to improve cohesion inside the matrix and the main consequence is the reduction of porosity inside the wall materials (Nishihora et al. [16]). With ceramic foam, neither SEM nor X-ray tomography analysis revealed melting or fusion of particles in the wall, which could cover the pores (Figure 6). Moreover, pore distribution between solid and ceramic foam remained almost the same (Figure 7). Sintering therefore had no significant impact on primary porosity.

Ceramic foams were slightly less dense than solid foams due to the loss of residual mass induced by the sintering step, which was not offset by loss of volume. This was confirmed by X-ray tomography analysis (Table 2), which showed that the average wall porosity of ceramic foams was greater than that of solid foams, implying minor impacts on porosity. If only porosity were considered, solid foams would have a stronger structure with fewer flaws than ceramic foams.

Many studies quantified the bubbles or pores in the foams using 2D analysis, leading to small numbers and lack of representativeness of the entire volume of foam. The smallest number of bubbles has been reported to be at least 500 (Mary [18]) and at least 500 pores in the present study. This number means that additional pores do not have a significant impact on pore size distribution. When the experimental X-ray tomography protocol was used, at least 5 times the limit value of pores was analysed. X-ray tomography turned out to be a powerful tool for the analysis of foam structure. This technique enables visualisation of foam wall and the 3D quantification of pores in the air fraction of the foam. X-ray tomography is also a nondestructive and rapid method, and analysis can be accomplished in a few minutes, or alternatively, a more detailed analysis can be performed depending on the degree of resolution required (up to $500 \mathrm{~nm}$ voxel size).

\subsection{Mechanical properties}

The foams studied here are brittle materials (Figure 4-2), and porosity governs at first order, the mechanical strength that decreases with increasing air fraction (Gibson and Ashby [24]). The mechanical properties $\left(E^{*}, \sigma^{*}\right.$ and $\left.F_{m}\right)$ of the materials are not exempt from this rule. When the wall thickness decreases due to an increase in pore size and a decrease in density, the wall becomes weaker and fractures rapidly appear, thereby reducing the mechanical properties. At low density $\left(<250 \mathrm{~kg} \cdot \mathrm{m}^{-3}\right)$ there is only a minor difference in mechanical properties between solid and ceramic foam, whereas at higher density (close to $500 \mathrm{~kg} \cdot \mathrm{m}^{-3}$ ) the difference is bigger.

If there is no increase in the number of cohesive bonds, it is probable that a reorganisation of matrix structure itself could improve the mechanical properties after sintering, for example, by reducing wall porosity. In ceramics, for instance, the porcelain sintering temperature has to be above $1,200{ }^{\circ} \mathrm{C}$ to achieve complete densification of the matrix (Sánchez et al. [42]). No evidence of either melting or fusion of wall particles was observed in ceramic foams, the improvement of mechanical properties after sintering therefore cannot be explained by this kind of matrix densification.

Higher sintering temperature should lead to partial or total densification of the matrix with additional risks like shrinkage or phase transition (melting or crystallisation). In this case the final product will be denser with better mechanical properties. Sintering at $950{ }^{\circ} \mathrm{C}$ improves 
the mechanical properties of the foams especially crushing and flexural strength without loss of porosity, demonstrating the ability of the material to enhance wall resistance without major changes in microstructure, thus limiting stress or cracking inside the material. One hypothesis is that sintering reduces the micro fragility of the walls and therefore increases the breaking strength $\left(F_{m}\right.$ and $\left.\sigma^{*}\right)$ without causing significant variation in the mechanical properties with only slight deformation (little variation in Young's modulus) with no significant difference in $E^{*}$ between solid and ceramic foams.

The presence of weakening phenomena like microcracks or large pores inside the wall, will have a more negative effect on the crushing strength of the material. "For brittle open-cell foams of same relative density, the crushing strength decreases with increasing cell size" (Gibson and Ashby [24]). This citation explains part of the standard deviation of foam values, meaning that the material has no monodisperse pore size distribution (Figure 7) or that microcracks are probably not visible to the naked eye. No major weakness was observed in the lighter foam studied here, which is very promising for applications that require a certain level of mechanical resistance in compression and insulation.

The crushing strength of solid and ceramic foams can be quite satisfactorily fitted with the Gibson and Ashby model. The better fitting for solid foam is probably explained by morphological aspects. The overall structure and the size of the foam pores do not change much (Figure 7) but shrinkage, microcracks or even small tears in the wall can appear locally, thereby modifying the pore and wall structure. Furthermore, sintering leads to mass and volume loss, implying reorganisation of the structure, which is globally offset because the density remains the same. The sintering step leads to deformation (weakening) and restructuration (enhanced cohesion) in the parts not concerned by Gibson and Ashby analysis, leading to less satisfactory fitting.

When Gibson and Ashby [24] applied their theory to other brittle foams, they suggested that the difficulty lay in the need to determine flaw size inside the wall to obtain a good estimation of $\sigma_{s .}$. Fracture-dominated structures, like foams with open-cell structure, have weak regions which reduce both stiffness and strength (Ashby [36]). This leads to lower mechanical property values than equivalent strength-dominated structure or ideal fracture-dominated structure (with no flaws). The latter perfectly follows Gibson and Ashby equations (Ashby [36]).

To determine crushing strength, Xu et al. [43] applied the Gibson and Ashby model and found that $C$ and $\alpha$ increased with pore size and post-heat treatment, thereby reducing the strength of the material. In our study, the result was different because sintering increased the crushing strength but did not significantly affect pore size. Pore geometry and especially transformation of the matrix could explain the increase in $C$ and $\alpha$. Gibson and Ashby equations give estimations correlated with $\sigma^{*}$ experimental trend of solid and ceramic foam. Using Gibson and Ashby's prediction, $\sigma$ of ceramic foam leads to high compressive resistance with very light mineral material (consequently insulating) for use in the building sector when relatively low conductivity $<0.050 \mathrm{~W} \cdot \mathrm{m}^{2} \cdot \mathrm{K}^{-1}$ is required (Abu-Jdayil et al. [44]).

$\mathrm{Xu}$ et al. [43] found that values of relative Young modulus were more affected by porosity than by pore size leading to slight variations in $C^{\prime}$ and $\beta$. These authors attributed variations in $C^{\prime}$ to pore geometry, whereas the variation in $\beta$ was attributed to unit cell size. In our study, 
the difference before and after sintering was quite small and almost symmetrical compared to theoretical value of $C^{\prime}$ and $\beta$ found by Gibson and Ashby.

The density of ultra-light concrete is below the range of foam densities studied with thermal conductivity of $0.045 \mathrm{~W} \cdot \mathrm{m}^{-1} \cdot \mathrm{K}^{-1}$ (Ytong [30]). The mechanical properties of lower density solid and ceramic foams (like ultra-light concrete) can be estimated using the Gibson and Ashby equation, and similar mechanical properties were found for foam materials. Mineral foams could thus be used for the same applications as ultra-light concrete, and provide better thermal resistance.

Mechanical properties depend on the structure and properties of the matrix. At equivalent density, light brick matrix has lower crushing strength in compression than solid foam. Both materials are composed of fired clay particles, but have different cohesive bonds and porosities, meaning solid foam has better bending properties. Mineral foam could also replace light brick with similar mechanical properties and lighter density, thereby saving raw material (lighter material) and energy in the process because of the energy-intensive sintering of brick in general with temperature $>1,300{ }^{\circ} \mathrm{C}$ (Zhang et al. [45]).

The 3-point bending test is more difficult to set up than the compressive test because of the brittle nature and dimensions of the sample. Some authors used other techniques to evaluate mechanical properties, including a 4 point bending test (Babiak et al. ([46]), Brazilian test (Belrhiti et al. [38]) or resonant frequency and impulse excitation techniques (Pabst et al. [14]).

Thus, a wide range of flexural strength or crushing strength is feasible without considerably increasing density, meaning the material can be used as structural or insulation material. In general, the lower the density, the lower the thermal conductivity (Samson [39], Asadi et al. [47]). Porosity weakens the mechanical strength of foams, but by adjusting the parameters that control primary and wall porosity, it is possible to have sufficient mechanical properties with low density.

\section{Conclusion}

This article explored the structure of foams using multiscale analysis combined with investigation of mechanical properties which are summarized in this section.

Porosity leads to a change in structure when the air fraction is increased. Larger pores were found in lighter foams by SEM and X-ray tomography analysis but the range of distribution was the same between the samples. Pores were distributed in an open continuous network made of two kinds of porosity. The main kind is primary porosity, which is created during foaming and extended in the drying step. The second kind is wall porosity made after matrix solidification and evaporation of water leaving small interconnected wall pores that are also connected with the larger pores resulting from primary porosity.

Mechanical properties are influenced by both porosity and the sintering step. At the microscale, pore and wall structures influence mechanical behaviour and the more air incorporated, the less efficient the mechanical properties will be. The wall structure does not change substantially after sintering, and there is no notable shrinkage or deformation of the 
structure. At $950{ }^{\circ} \mathrm{C}$, no sintering occurs between particles, with little impact in the case of slight deformation (low Young modulus variation) while important mechanical properties increase significantly in the case of major deformation (marked variations in crushing and flexural strength). The impact of sintering was clearly demonstrated by comparison with crushing and flexural strength data on solid and ceramic foams.

Power law models fit solid and ceramic foams satisfactorily. The Gibson and Ashby models were less correlated with experimental data because of the difficulty involved in properly estimating the intrinsic properties of the matrix, multimodal distribution and pore geometry. The lower degree of correlation with ceramic foam is attributed to changes in structure and mechanical properties that occurred during the sintering step.

The commercial samples tested in this study had lower or similar mechanical properties than those of mineral foams (at similar density), especially concerning flexural strength where light bricks cannot be characterised because of their brittleness. By reducing density values to those of ultra-light concrete, mineral foams could probably be used in similar applications with better thermal properties.

All these investigations show that it is possible to manage and predict mechanical properties with control foaming and sintering treatment to obtain light and sufficiently strong material. The mineral foams tested in this study are a really innovative way to construct a non-fibrous, breathable, safe, and efficient building and can be used in countless applications (furnace insulating panels, fire doors, burners, etc.) thanks to their refractory and mechanical properties. They will facilitate the recycling of construction wastes (bricks, slate, clay, etc) or upcycling of mineral powder from deposits.

\section{Acknowledgements}

This work was supported by grants from ANRT and IPSIIS. The authors would like to thank Pablo Granda from AgroParisTech for his help measuring the mechanical properties of foams. Acknowledgement is also due to Région Grand Est, Département de la Marne, Grand Reims and the European Union for supporting the Centre Européen de Biotechnologie et de Bioéconomie (CEBB 51110 Pomacle, France), where this study was carried out. For a threeyear period (from 01/05/2016 to 30/04/2019) and with a total budget of 965.000€, 3D-BioMat is co-financed by Grand Reims (31\%) and the European Union by $48.7 \%$ (i.e. $50 \%$ of eligible expenditure). Europe is committed to the Grand Est with the European Regional Development Fund. Finally, the authors are especially grateful to the IPSIIS team, Yves Le Corfec and Alexandre Bordenave who helped conduct the technical and developmental analyses of the mineral products.

The raw/processed data required to reproduce these findings cannot be shared at this time due to technical or time limitations.

\section{References}

[1] D. D'Agostino, B. Cuniberti, P. Bertoldi, Energy consumption and efficiency technology measures in European non-residential buildings, Energy and Buildings. 153 (2017) 7286. doi:10.1016/j.enbuild.2017.07.062.

[2] Organisation for Economic Co-Operation and Development, Energy Technology Perspectives 2017: Catalysing Energy Technology Transformations, OECD, 2017. 
[3] M.M Fragos, Trouillez, Le guide de l'isolation, Fine Media-Solocal Group, Paris, 2012. https://isolation.ooreka.fr/ebibliotheque/liste.

[4] R.J. Flatt, N. Roussel, C.R. Cheeseman, Concrete: An eco material that needs to be improved, Journal of the European Ceramic Society. 32 (2012) 2787-2798. doi:10.1016/j.jeurceramsoc.2011.11.012.

[5] P. Clément, Détermination des propriétés mécaniques de céramiques poreuses par essais de microindentation instrumentée sphérique, PhD thesis, INSA de Lyon, 2013.

[6] S. Liu, K. Zhu, S. Cui, X. Shen, G. Tan, A novel building material with low thermal conductivity: Rapid synthesis of foam concrete reinforced silica aerogel and energy performance simulation, Energy and Buildings. 177 (2018) 385-393. doi:10.1016/j.enbuild.2018.08.014.

[7] T. Shimizu, K. Matsuura, H. Furue, K. Matsuzak, Thermal conductivity of high porosity alumina refractory bricks made by a slurry gelation and foaming method, Journal of the $\begin{array}{lllll}\text { European } & \text { Ceramic } & \text { Society. } & 33 & \text { (2013) }\end{array}$ doi:10.1016/j.jeurceramsoc.2013.07.001.

[8] L.J. Fennelly, M.A. Perry, 150 Things You Should Know about Security, ButterworthHeinemann, 2018. doi:10.1016/B978-0-12-809485-3.00001-6.

[9] Promat, Isolation haute température - Promat, (2019). https://www.promat-hpi.com/frfr/avantages/isolation-haute-température (accessed February 19, 2019).

[10] SISTAC, L'isolation Haute Température de A à Z, (2019). http://www.sistacalizay.fr/Catalogue/index.php (accessed February 19, 2019).

[11] M. Scheffler, P. Colombo, Cellular Ceramics: Structure, Manufacturing, Properties and Applications, WILEY-VCH Verlag GmbH \& Co. KGaA, Weinheim, 2005.

[12] A.R. Studart, U.T. Gonzenbach, E. Tervoort, L.J. Gauckler, Processing Routes to Macroporous Ceramics: A Review, Journal of the American Ceramic Society. 89 (2006) 1771-1789. doi:10.1111/j.1551-2916.2006.01044.x.

[13] P. Colombo, Conventional and novel processing methods for cellular ceramics, Philos Trans A Math Phys Eng Sci. 364 (2006) 109-124. doi:10.1098/rsta.2005.1683.

[14] W. Pabst, E. Gregorová, I. Sedlářová, M. Černý, Preparation and characterization of porous alumina-zirconia composite ceramics, Journal of the European Ceramic Society. 31 (2011) 2721-2731. doi:10.1016/j.jeurceramsoc.2011.01.011.

[15] E.C. Hammel, O.L.-R. Ighodaro, O.I. Okoli, Processing and properties of advanced porous ceramics: An application based review, Ceramics International. 40 (2014) 15351-15370. doi:10.1016/j.ceramint.2014.06.095.

[16] R.K. Nishihora, P.L. Rachadel, M.G.N. Quadri, D. Hotza, Manufacturing porous ceramic materials by tape casting-A review, Journal of the European Ceramic Society. 38 (2018) 988-1001. doi:10.1016/j.jeurceramsoc.2017.11.047.

[17] A.B.J. Kroezen, J. Groot Wassink, E. Bertlein, Foam generation in a rotor-stator mixer: schaumerzeugung in einem rotor-stator mischer, Chemical Engineering and Processing: Process Intensification. 24 (1988) 145-156. doi:10.1016/02552701(88)80018-7.

[18] G. Mary, Prise en compte des e $\square$ ets du produit et du procédé au cours de l'opération de foisonnement par battage en continu - Analyse dimensionnelle, PhD thesis, AgroParisTech, 2011. https://pastel.archives-ouvertes.fr/pastel-00780633/document (accessed February 11, 2019).

[19] W. Drenckhan, A. Saint-Jalmes, The science of foaming, Advances in Colloid and Interface Science. 222 (2015) 228-259. doi:10.1016/j.cis.2015.04.001.

[20] A.S. Mujumdar, Handbook of Industrial Drying: 3rd (Third) edition, CRC Press, 2006.

[21] J. Vasseur, Séchage: principes et calcul d'appareils Séchage convectif par air chaud (partie 1), Techniques de l'ingénieur Opérations Unitaires : Évaporation et Séchage. base 
documentaire: TIB316DUO. (2009). https://www.techniques-ingenieur.fr/basedocumentaire/procedes-chimie-bio-agro-th2/operations-unitaires-evaporation-etsechage-42316210/sechage-principes-et-calcul-d-appareils-j2451/.

[22] J. Vasseur, Séchage industriel : principes et calcul d'appareils Séchage convectif par air chaud (partie 2), Techniques de l'ingénieur Opérations Unitaires: Évaporation et Séchage. base documentaire: TIB316DUO. (2010). https://www.techniquesingenieur.fr/base-documentaire/procedes-chimie-bio-agro-th2/operations-unitairesevaporation-et-sechage-42316210/sechage-industriel-principes-et-calcul-d-appareilsj2452/.

[23] R.M. German, 1 - Thermodynamics of sintering, in: Z.Z. Fang (Ed.), Sintering of Advanced Materials, Woodhead Publishing, 2010: pp. 3-32. doi:10.1533/9781845699949.1.3.

[24] L.J. Gibson, M.F. Ashby, Cellular Solids: Structure and Properties, Cambridge University Press, 1999.

[25] A. Bouterf, E. Maire, S. Roux, F. Hild, X. Brajer, E. Gouillart, E. Boller, Analysis of compaction in brittle foam with multiscale indentation tests, Mechanics of Materials. 118 (2018) 22-30. doi:10.1016/j.mechmat.2017.12.004.

[26] M.A. Vicente, D.C. González, J. Mínguez, Recent advances in the use of computed tomography in concrete technology and other engineering fields, Micron. 118 (2019) 22-34. doi:10.1016/j.micron.2018.12.003.

[27] J. Maier, T. Behnisch, V. Geske, M. Ahlhelm, D. Werner, T. Moritz, A. Michaelis, M. Gude, Investigation of foam structure formation in the Freeze Foaming process based on in-situ computed tomography, Results in Physics. 11 (2018) 584-590. doi:10.1016/j.rinp.2018.08.038.

[28] Y. Le Corfec, Process for the preparation of solid porous mineral foams and their uses, EP3225607A1, 2017. https://patents.google.com/patent/EP3225607A1/en (accessed February 8, 2019).

[29] Skamol, SkamoCeramic Hipor 450 datasheet, (2019). https://www.skamol.com/shop/product/skamoceramic-hipor-450 (accessed February 11, 2019).

[30] Ytong, Ytong Multipor - Le système par excellence pour isoler ... - Ecobati, Pdfhall.Com. (2019). https://pdfhall.com/ytongmultipor-le-systeme-par-excellence-pourisoler-ecobati_598b56ff1723dd15846fa382.html (accessed February 8, 2019).

[31] P. Perré, F. Huber, Measurement of free shrinkage at the tissue level using an optical microscope with an immersion objective: results obtained for Douglas fir (Pseudotsuga menziesii) and spruce (Picea abies), Ann. For. Sci. 64 (2007) 255-265. doi:10.1051/forest:2007003.

[32] G. Almeida, F. Huber, P. Perre, Free shrinkage of wood determined at the cellular level using an environmental scanning electron microscope, MADERAS: Ciencia y Tecnología. 16 (2014) 187-198. doi:10.4067/S0718-221X2014005000015.

[33] P. Perré, Meshpore: A Software Able to Apply Image-Based Meshing Techniques to Anisotropic and Heterogeneous Porous Media, Drying Technology. 23 (2005) 19932006. doi:10.1080/07373930500210432.

[34] AFNOR, Wood-based panels. Determination of modulus of elasticity in bending and of bending strength, NF EN 310, (1993) 8.

[35] I. Cantat, S. Cohen-Addad, F. Elias, F. Graner, R. Höhler, O. Pitois, F. Rouyer, A. SaintJalmes, Foams: Structure and Dynamics, 1st ed., OUP Oxford, 2013.

[36] M.F. Ashby, The properties of foams and lattices, Philosophical Transactions of the Royal Society A: Mathematical, Physical and Engineering Sciences. 364 (2006) 15-30. doi:10.1098/rsta.2005.1678. 
[37] M.F. Ashby, D.R.H. Jones, Matériaux - 4e éd. - T1 Propriétés, applications et conception, 4e édition, Dunod, Paris, 2013.

[38] Y. Belrhiti, J.C. Dupre, O. Pop, A. Germaneau, P. Doumalin, M. Huger, T. Chotard, Combination of Brazilian test and digital image correlation for mechanical characterization of refractory materials, Journal of the European Ceramic Society. 37 (2017) 2285-2293. doi:10.1016/j.jeurceramsoc.2016.12.032.

[39] G. Samson, Synthèse et propriétés des mousses minérales, PhD thesis, Rennes, INSA, 2015. http://www.theses.fr/2015ISAR0015 (accessed February 26, 2019).

[40] H. Bey, F. Wintzenrieth, O. Ronsin, R. Höhler, S. Cohen-Addad, Stabilization of foams by the combined effects of an insoluble gas species and gelation, Soft Matter. 13 (2017) 6816-6830. doi:10.1039/C6SM02191C.

[41] L.R. Glicksman, Heat transfer in foams, in: N.C. Hilyard, A. Cunningham (Eds.), Low Density Cellular Plastics: Physical Basis of Behaviour, Springer Netherlands, Dordrecht, 1994: pp. 104-152. doi:10.1007/978-94-011-1256-7_5.

[42] E. Sánchez, J. García-Ten, V. Sanz, A. Moreno, Porcelain tile: Almost 30 years of steady scientific-technological evolution, Ceramics International. 36 (2010) 831-845. doi:10.1016/j.ceramint.2009.11.016.

[43] Y. Xu, D. Zhang, S. Hu, R. Chen, Y. Gu, X. Kong, J. Tao, Y. Jiang, Mechanical properties tailoring of topology optimized and selective laser melting fabricated Ti6Al4V lattice structure, Journal of the Mechanical Behavior of Biomedical Materials. (2019). doi:10.1016/j.jmbbm.2019.06.021.

[44] B. Abu-Jdayil, A.-H. Mourad, W. Hittini, M. Hassan, S. Hameedi, Traditional, state-ofthe-art and renewable thermal building insulation materials: An overview, Construction and Building Materials. 214 (2019) 709-735. doi:10.1016/j.conbuildmat.2019.04.102.

[45] Z. Zhang, Y.C. Wong, A. Arulrajah, S. Horpibulsuk, A review of studies on bricks using alternative materials and approaches, Construction and Building Materials. 188 (2018) 1101-1118. doi:10.1016/j.conbuildmat.2018.08.152.

[46] M. Babiak, M. Gaff, A. Sikora, Š. Hysek, Modulus of elasticity in three- and four-point bending of wood, Composite Structures. $204 \quad$ (2018) 454-465. doi:10.1016/j.compstruct.2018.07.113.

[47] I. Asadi, P. Shafigh, Z.F.B. Abu Hassan, N.B. Mahyuddin, Thermal conductivity of concrete - A review, Journal of Building Engineering. 20 (2018) 81-93. doi:10.1016/j.jobe.2018.07.002. 


\section{Declaration of interests}

$\bigotimes$ The authors declare that they have no known competing financial interests or personal relationships that could have appeared to influence the work reported in this paper.

$\square$ The authors declare the following financial interests/personal relationships which may be considered as potential competing interests: 